\title{
2 L ARQUITECTO CARMELITA FRAY JOSÉ ALBERTO PINA VERSUS EL GREMIO DE ALBAÑILES DE ZARAGOZA (1731-1735)
}

REBECA CARRETERO CALVO

Departamento de Historia del Arte. Universidad de Zaragoza rcc@unizar.es

\begin{abstract}
Resumen: Este artículo da a conocer y analiza el pleito que el carmelita calzado fray José Alberto Pina interpuso al gremio de albañiles de Zaragoza en 1731 por impedir su acceso al grado de maestro. La asociación zaragozana basó su defensa en dos motivos: la condición de religioso de Pina, y su formación incompleta. Sin embargo, pese a que a lo largo de la causa se demostró que ambas cuestiones, legalmente, no eran óbice para que el fraile optara a la maestría, el gremio consiguió imponerse. Ante el fracaso, fray José Alberto fue trasladado por su Orden primero a la diócesis de Tarazona y después a Levante, territorios en los que desarrolló una intensa y destacada actividad arquitectónica.
\end{abstract}

Palabras clave: Fray José Alberto Pina / pleito civil / gremio / arquitecto / maestro de obras / Zaragoza / siglo XVIII.

\section{THE ARCHITECT CARMELITE FRAY JOSÉ ALBERTO PINA VERSUS THE MASONS GUILD OF SARAGOSSA (1731-1735)}

Abstract: This article gives to know and analyzes the lawsuit that the carmelite fray José Alberto Pina interposed to the guild of masons of Saragossa in 1731 to prevent its access to the degree of master. The association based its defense on two reasons: the condition of religious of Pina, and its incomplete formation. However, despite the fact that throughout the case it was demonstrated that both were, legally, not an obstacle for the friar to opt for mastery, the guild managed to impose itself. Faced with the failure, fray José Alberto was transferred by his Order first to the diocese of Tarazona and then to Levante, territories in which he developed an intense and outstanding architectural activity.

Keywords: Fray José Alberto Pina / lawsuit / guild / architect / mason / Saragossa / 18th century

\section{Introducción}

La formación arquitectónica de los más importantes tracistas y maestros de obras españoles de los siglos XVII y XVIII pertenecientes a las distintas órdenes religiosas asentadas en nuestro país suele ser una incógnita. Este es el caso, por ejemplo, del afamado carmelita descalzo fray Alberto de la Madre de Dios (1575-1635), que no contó con antecedentes familiares en el oficio por lo que debió aprenderlo en el seno de la Orden; ${ }^{1}$ del también descalzo fray José de la Concepción (1626-1689),

\footnotetext{
* Fecha de recepción: 15 de abril de 2018 / Fecha de aceptación: 9 de mayo de 2018.

** Esta investigación se ha desarrollado en el marco del Grupo de Investigación de Referencia Vestigium (H19_17R), financiado por el Departamento de Innovación, Investigación y Universidad del Gobierno de Aragón y el programa operativo FEDER Aragón 2014-2020.

1 MUÑOZ JIMÉNEZ, José Miguel, Fray Alberto de la Madre de Dios. Arquitecto (1575-1635). Santander: Ediciones Tantín, 1990, pp. 15-19.
} 
probablemente en la misma situación que el anterior; ${ }^{2}$ del agustino recoleto fray Lorenzo de San Nicolás (1593-1679) que, aunque era hijo del maestro de obras madrileño Juan Martínez, no se inició en este arte con su padre sino con un desconocido artífice; ${ }^{3}$ o del jerónimo fray Antonio de San José Pontones (1710-1774) que, si bien se considera que debió llevar a cabo el aprendizaje con su progenitor e incluso que pudo ser examinado por el gremio de Valladolid, no se ha hallado constancia documental que lo confirme. ${ }^{4}$

En esta misma situación debíamos encuadrar al carmelita observante aragonés fray José Alberto Pina (1693-1772), considerado uno de los más cualificados maestros de obras de Aragón y Valencia durante el siglo XVIII. Hasta ahora únicamente se intuía que su instrucción debió llevarse a cabo junto a alguno -o algunos- de los arquitectos zaragozanos a cargo de las más importantes obras de comienzos del siglo XVIII, enriquecida, como se desprende de sus declaraciones localizadas sobre los edificios que reconoció, con la lectura de los tratados arquitectónicos más empleados en la época, como los de fray Lorenzo de San Nicolás, Juan Caramuel, Vicente Tosca ${ }^{5}$ o Andrea Pozzo. ${ }^{6}$ Sin embargo, el hallazgo del pleito que Pina interpuso al gremio de albañiles de Zaragoza en 1731, conservado en el Archivo Histórico Provincial de la capital aragonesa, ofrece información relevante, hasta el momento totalmente inédita, acerca de sus primeros pasos en este arte y de los obstáculos e inconvenientes que la corporación zaragozana puso al religioso para desempeñar su oficio en la ciudad y que, probablemente, motivaron su salida de ella. Asimismo, este proceso permite comprender mejor el funcionamiento del sistema gremial en el Antiguo Régimen, su endogamia corporativa y la oligarquización de sus cargos.

De este modo, en este texto se presenta, en primer lugar, una aproximación al gremio de albañiles de Zaragoza para, a continuación, analizar con detalle el contenido de este pleito, reproduciendo algunas frases y párrafos dignos de mención literal con la intención de acercarnos lo más directa y asépticamente posible al problema. Asimismo, se recogen los nombres y los datos conocidos de los maestros de obras implicados en la causa, se revisan brevemente los términos de arquitecto, albañil, maestro de obras y alarife empleados en el texto documental, y se completa, en la medida de lo posible, la biografía de fray José Alberto Pina, todavía inconclusa.

\section{El gremio de albañiles de Zaragoza}

A partir de la década de 1980 se empezaron a cubrir las grandes lagunas existentes en el estudio de los gremios aragoneses durante la Edad Moderna gracias a la contribución de diversos investigadores. La primera gran aportación fue la del profesor Guillermo Redondo, que dedicó su tesis doctoral al estudio de las corporaciones de artesanos de Zaragoza en el siglo XVII, publicada en 1982. ${ }^{7}$ En cuanto a los gremios y profesiones vinculadas al arte, los principales y primeros trabajos fueron los de Ángel San Vicente y Juan Francisco Esteban sobre los plateros de los siglos XVI al $\mathrm{XVIII}^{8}$ de Belén Boloqui sobre el gremio de carpinteros, ensambladores, entalladores y escultores en los siglos XVII y XVIII, ${ }^{9}$ de Carmen Gómez sobre

\footnotetext{
2 NARVÁEZ CASES, Carme, El tracista fra Josep de la Concepció i l'arquitectura carmelitana a Catalunya. Barcelona: Universidad Autónoma de Barcelona, 2000, p. 139-144. Tesis doctoral en línea disponible en http://www.tdx.cat/handle/10803/5187 (fecha de consulta: 30/07/2017); y NARVÁEZ CASES, Carme, El tracista Fra Josep de la Concepció (1626-1690). Barcelona: Curial Edicions Catalanes y Fundació Abadia de Monserrat, 2004, p. 41.

${ }^{3}$ DÍAZ MORENO, Félix, Fray Lorenzo de San Nicolás: Arte y vso de arquitectvra. Edición anotada. Madrid: Instituto de Estudios Madrileños, 2008, pp. XXVII-XXVIII.

${ }^{4}$ CANO SANZ, Pablo, Fray Antonio de San José Pontones: arquitecto, ingeniero y tratadista en España, (1710-1774). Madrid: Universidad Complutense de Madrid, 2004, pp. 51-55. Tesis doctoral disponible en línea en http://biblioteca.ucm.es/ tesis/ghi/ucm-t27479.pdf (fecha de consulta: 30/07/2017); y CANO SANZ, Pablo. Fray Antonio de San José Pontones. Arquitecto jerónimo del siglo XVIII. Madrid: Consejo Superior de Investigaciones Científicas, 2005, pp. 17-20.

${ }^{5}$ AZANZA LÓPEZ, José Javier, "Tracistas y maestros de obras aragoneses en la arquitectura barrroca navarra". Boletín del Museo e Instituto "Camón Aznar", LXXI, 1998 a, p. 11.

${ }^{6}$ CARRETero CAlvo, Rebeca, "Recepción del tratado del jesuita Andrea Pozzo en Aragón". Locus Amoenus, 15, 2017, pp. 131132.

7 REDONDO VEINTEMILLAS, Guillermo, Las corporaciones de artesanos de Zaragoza en el siglo XVII. Zaragoza: Institución "Fernando el Católico", 1982.

8 SAN VICENTE PINO, Ángel, La platería de Zaragoza en el Bajo Renacimiento (1545-1599), 3 vols. Zaragoza: Libros Pórtico, 1976; y ESTEBAN LORENTE, Juan Francisco, La platería de Zaragoza en los siglos XVII y XVIII, 3 vols. Madrid: Ministerio de Cultura, 1981.

9 BOLOQUI LARRAYA, Belén, Escultura zaragozana en la época de los Ramírez. 1710-1780, 2 vols. Madrid: Ministerio de Cultura, 1983, vol. I, pp. 25-50.
} 
el gremio de obreros de villa hasta $1620,{ }^{10}$ de Manuel Expósito sobre el gremio de canteros y el de albañiles entre la segunda mitad del siglo XVIII y comienzos del XIX, ${ }^{11}$ de Vicente González sobre la cofradía de pintores y doradores en los siglos XVI y XVII ${ }^{12}$ y de Arturo Ansón sobre el gremio de doradores de Zaragoza entre 1675 y $1820 .^{13}$ Más recientemente, el profesor Jesús Criado en su tesis doctoral se encargó de analizar los gremios artísticos aragoneses durante el Segundo Renacimiento $(1540-1580) .^{14}$

Un gremio es una corporación privilegiada de ámbito local, integrada por todos los artesanos de un mismo oficio. Sus objetivos son tres: defender sus intereses profesionales; tutelar a sus miembros asumiendo una previsión social; y facilitar el control de su producción por parte de las autoridades municipales. Además, los componentes de un gremio podían reunirse en una cofradía que era la agrupación de los trabajadores gremiales amparados por la Iglesia con un objetivo definido. La cofradía vigilaba el oficio, ejercía una labor benéfico-asistencial y regulaba quiénes podían acceder al ejercicio profesional a través del control del examen de maestría.

En el Renacimiento los gremios seguían rigiendo la formación, las categorías profesionales, el acceso al grado de maestro o la práctica del oficio, tal y como lo habían hecho durante la Edad Media. Sin embargo, en el siglo XVI algunos oficios artísticos, como los ensambladores, entalladores, mazoneros e imagineros, carecieron de asociación gremial propia. Esta circunstancia conllevó que en las prin- cipales ciudades aragonesas dichos oficios se integrasen en el mismo gremio que los maestros de obras, cuberos, torneros y carpinteros. El caso más conocido es el de la ciudad de Zaragoza: su cofradía fue creada a finales del siglo XIV y estaba dedicada a la Transfiguración, San Esteban y San José, ${ }^{15}$ aunque en 1619 decidieron disgregarse.

Al año siguiente, en 1620, los obreros de villa zaragozanos redactaron sus propias ordinaciones ${ }^{16} \mathrm{y}$ apenas una década más tarde, en 1628, los ensambladores, entalladores y escultores se unieron a los anteriores constituyendo un único gremio y una sola cofradía. No obstante, en 1655 se separaron para conformar una sola asociación. ${ }^{17}$ En 1613 los torneros ya se habían disociado de los carpinteros, mientras que los cuberos aprobaron sus ordenanzas en $1654 .^{18}$

Este fenómeno de agrupación de varios oficios en una única corporación fue algo generalizado, aunque a medida que avanzaba el siglo XVII se hizo habitual que se fueran disolviendo según sus especializaciones, sobre todo en ciudades de importancia, como ocurrió en Zaragoza. No obstante, en localidades zaragozanas de menor población, entre las que se encuentran Tarazona ${ }^{19}$ o Borja, ${ }^{20}$ la fusión de oficios relacionados con una rama determinada de la producción, como la de la construcción, siguió activa ${ }^{21}$ hasta su desaparición a comienzos del siglo XIX.

Como ya se ha apuntado, uno de los gremios zaragozanos más importantes en materia artística fue el de albañiles, cuya cofradía, bajo la advocación de la Transfiguración, San Esteban y San José,

10 GÓMEZ URDÁÑEZ, Carmen, Arquitectura civil en Zaragoza en el siglo XVI, 2 vols. Zaragoza: Ayuntamiento de Zaragoza, 1988, vol. II, pp. 13-68.

11 EXPÓSITO SEBASTIÁN, Manuel, "El gremio de canteros de Zaragoza (1760-1812)". Artigrama, 1, 1984, pp. 269-286; y EXPÓSITO SEBASTIÁN, Manuel, "El gremio de albañiles de Zaragoza (1775-1806)". Artigrama, 2, 1985, pp. 161-176.

12 GONZÁLEZ HERNÁNDEZ, Vicente, "Cofradías y gremios zaragozanos en los siglos XVI y XVII: La Cofradía de San Lucas de pintores". Zaragoza, XXV, 1967, pp. 175-190.

13 ANSÓN NAVARRO, Arturo, "El gremio de doradores de Zaragoza (1675-1820)". En: Homenaje a don Federico Balaguer Sánchez. Huesca: Instituto de Estudios Altoaragoneses, 1987, pp. 485-511.

${ }_{14}$ CRIADO MAINAR, Jesús, Las artes plásticas del Segundo Renacimiento en Aragón. Pintura y Escultura 1540-1580. Tarazona: Centro de Estudios Turiasonenses e Institución "Fernando el Católico", 1996.

15 Ibidem, pp. 18-20.

16 GÓMEZ URDÁÑEZ, Carmen, 1988, vol. II, pp. 13-68.

17 BOLOQUI LARRAYA, Belén, 1983, vol. I, pp. 25-50.

18 REDONDO VEINTEMILLAS, Guillermo, 1982, p. 91; y GÓMEZ URDÁÑEZ, Carmen, 1988, vol. Il, p. 13. Sobre lo sucedido en localidades como Huesca, Barbastro o Épila, véase CRIADO MAINAR, Jesús, 1996, pp. 20-22.

19 CARRETERO CALVO, Rebeca, "El gremio de albañiles y carpinteros de Tarazona durante la Edad Moderna". Artigrama, 26, 2011, pp. 603-624.

20 AGUILERA HERNÁNDEZ, Alberto, "La cofradía de San José de la ciudad de Borja: su fundación en la colegiata de Santa María y el exorno de su capilla titular (1625-1694)". Artigrama, 30, 2015, pp. 241-259.

${ }^{21}$ EXPÓSITO SEBASTIÁN, Manuel, 1985, p. 169 y tabla n 4, p. 172; y GÓMEZ URDÁÑEZ, Carmen, 1988, vol. II, p. 13. 
tenía su sede en el convento de San Francisco. Para el 11 de agosto de 1620 ya habían redactado sus ordinaciones que conocemos gracias a una copia de 10 de julio de 1727 conservada en el Archivo Municipal de Zaragoza. ${ }^{22}$ Estas estipulaban que la cofradía debía estar presidida por dos mayordomos, uno de bolsa -encargado de custodiar el libro de las ordinaciones y de ceder su casa para realizar los exámenes del gremio- y otro de cofre, elegidos anualmente [ordinaciones núms. 1 y 3]. Asimismo, debía existir un "luminero", encargado de mediar y "poner paz" entre los miembros de llegar el caso [ordinación $\left.n^{\circ} 17\right]$; los consejeros o "prohombres", que asistían a los exámenes de los futuros maestros para asesorar [ordinación $n^{\circ}$ 5], cargo que recaía en los mayordomos del año anterior [ordinación $n^{\circ} 23$ ]; los veedores, que velaban por los intereses profesionales de la corporación y controlaban la calidad de las obras levantadas por los agremiados; el andador, corredor y llamador, encargado de presenciar el repaso y estado de las cuentas; y el notario de la agrupación, necesario para dar traslado de todo lo decidido por la cofradía. ${ }^{23}$

El primer paso para acceder al gremio era el aprendizaje ligado a un maestro durante cuatro años, tiempo que debía cumplirse inexorablemente [ordinación $n^{\circ}$ 18]. Al final de ese periodo el aprendiz pasaba al estadio de mancebo, por un tiempo no superior a ocho años, desarrollados tanto en la ciudad de Zaragoza como en cualquier otra [ordinación $n^{\circ} 6$ ]. Concluido este plazo, para ingresar en el gremio se debía superar un examen, consistente en realizar dos trazas, "allende del modelo y la otra diferente" [ordinación $n^{\circ} 7$ ], pagando además por este requisito 20 escudos en concepto de gastos a repartir entre los oficiales examinantes y la cofradía. No obstante, si el examinado era hijo de cofrade debía abonar únicamente la mitad [ordinación $n^{\circ} 8$ ]. Una vez aprobado el examen, el oficial podría construir "qualquiere edificio que se ofreciere en la ziudad o en el distritu de ella, como sea cassas, yglessias, capillas, torres, puentes, molinos, poniendo y tomando por su quenta todo lo que fuere necessario para dichos edificios de ladrillo, algez, piedras, rexas, rexados, vidrio, alabastros y madera gruessa por labrar", pues la labrada la debían realizar los car- pinteros "examinados" [ordinación $n^{\circ}$ 9]. Además, a quien el gremio localizara trabajando sin haber superado el examen "le quiten la herramienta", siendo sancionado con 60 sueldos jaqueses de multa [ordinación $\left.n^{\circ} 11\right]$. Sin embargo, existía la posibilidad de que un obrero de villa no examinado pudiera desempeñar su labor en la ciudad previa licencia expresa de los mayordomos de la cofradía, y supeditada esta a la presencia de albañiles reconocidos en la ciudad que pudieran hacerse cargo de la obra en cuestión [ordinación $\left.n^{\circ} 10\right]$.

Igualmente, las ordenanzas determinaban cuestiones más perentorias como lo relativo a los entierros de los cofrades [ordinaciones núms. 12, 13, 14 y 28], de la asistencia a los oficios divinos [ordinaciones núms. 19 y 20], del juramento y aceptación de los cargos de la cofradía [ordinaciones núms. 15, 16 y 30], de las cuentas [ordinaciones núms. 24, 25 y 26], del ingreso de las segundas esposas de los cofrades [ordinación $n^{\circ} 28$ ] y de cómo orientar la disposición de los tejados para evitar que las aguas produjeran menoscabo a los vecinos [ordinación $\left.n^{\circ} 29\right] .^{24}$

La copia de estas ordenanzas incluye tres adiciones. La primera está datada el 3 de diciembre de 1627 que modificó la ordinación $n^{\circ} 10$ prohibiendo a cualquier oficial no examinado "trabajar a solas o en compañia de otro oficial examinado o no" en la ciudad sin licencia de los mayordomos. Además, incluyó en la misma que "el oficial que hiciere o comenzare qualquiere obra la haia de proseguir y prosiga, y si el dueño de la obra no quiere la prosiga no puede otro oficial intrometerse ni proseguirla a fin que el oficial que la comenzo sea primero pagado de lo que huviere travajado y hecho en dicha obra", citando el caso concreto de Francisco Guallarte. La segunda adición, de 28 de noviembre de 1634, varió el importe del examen a 30 libras jaquesas. Asimismo, eximió a Diego Borbón "el tiempo que como aprendiz havia de haver servado". La tercera enmienda, fechada el 4 de diciembre de 1647, rectificó el sistema de evaluación de acceso al oficio debido a que se detectaron irregularidades. De hecho, el texto especificaba que "le es facil al que se ha de examinar tener noticia de" las dos trazas que debía llevar a cabo, "y prevenirse para estar adverti-

\footnotetext{
22 Archivo Municipal de Zaragoza [A.M.T.], Signatura 19-10, Ordinaciones del gremio de albañiles, 1620. Esta copia fue realizada por el escribano zaragozano Francisco Martínez cotejando las ordenanzas de la cofradía del gremio proporcionadas por el maestro de obras Manuel de Sanclemente, vecino de Zaragoza.

${ }^{23}$ Aunque las ordinaciones únicamente nombran estos últimos cargos sin definir sus labores. Para mayor información sobre ellos puede consultarse GÓMEZ URDÁÑEZ, Carmen, 1988, vol. II, pp. 21-25.

${ }^{24}$ A.M.T., Signatura 19-10, Ordinaciones del gremio de albañiles, 1620, ff. 2-6.
} 
do del intento del examen y dar satisfaccion de el". De esta manera, los postulantes "entravan a ser examinados sin havilidad y pericia que dispone dicho arte". Al mismo tiempo, se deseaba "aliviar a los examinantes de la ocupacion y tiempo que empleavan en disponer y fabricar el modelo de la traza que se les señalava" para efectuar las pruebas. Por todo ello, mudaron el tipo de examen de tal modo que a partir de entonces consistiría en la realización de dos trazas "y de la una haia de hacer planta, perfil y modelo de yesso", a petición del mayordomo de bolsa, mientras que el de cofre "le pueda pedir a solas dos trazas" más, "las que le pareciere convenientes, segun la havilidad de dicho examinante". Además, también se podría solicitar al candidato alguna montea la cual "la haia de señalar, cortar y armarla sobre una tabla".

A estas adiciones se sumó la ratificación de las ordenanzas 9 y 10, datada el 24 de octubre de 1663, por las que, como se vio, solo los obreros de villa examinados o los provistos de licencia expresa de los mayordomos de la cofradía del gremio podían desempeñar su trabajo en la ciudad. No obstante, el 3 de diciembre del año siguiente, los cofrades decidieron incluir un nuevo estatuto por el que "todos los que no son maestros examinados" por la cofradía tenían obligación de "pagar cada uno de ellos un real cada semana para el cuerpo de dicha cofradia y socorrer las necesidades de aquella, y que esto se entendiesse assi con los que travajan en esta ziudad como en sus terminos y varrios". Esta nueva ordinación tuvo efecto hasta el 12 de diciembre de 1720 pues, fundamentalmente, estaba destinada para los mancebos albañiles de la ciudad resultándoles abusiva, razón por la que, tras el dictamen de "los adbogados ordinarios" de Zaragoza, fue derogada. ${ }^{25}$

Sin embargo, en 1731 el carmelita observante fray José Alberto Pina se vio en la necesidad de demandar al gremio de maestros de obras de la ciudad del Ebro para denunciar el incumplimiento de las ordenanzas 6, 7 y 18, por las que, como se recordará, el aprendiz, tras concluir su estancia de cuatro años de duración con el maestro, pasaba al grado de mancebo en el que debía permanecer un tiempo no superior a ocho años, ya fuera en la ciudad de Zaragoza o en cualquier otra, periodo tras el que el gremio debía admitirle a examen. Como se comprobará en las páginas que siguen, Pina defendía que había completado su aprendizaje y exigía ser examinado para poder obtener el grado de maestro.

\section{Los hechos}

El 3 de julio de 1731 fray José Alberto Pina, carmelita observante del convento de Zaragoza, nombró como su representante a pleitos a José Forniés, procurador de número de la Real Audiencia del Reino de Aragón. En la concisa licencia -que se inserta- que fray Blas Fernández, prior de su cenobio y vicario provincial de su Orden, le otorgó el 14 de junio del mismo año se expresaba la razón por la que Pina requería este trámite: "para que pida en justicia el examen de maestro arbañil en el Tribunal del señor tiniente corregidor doctor Fernando Moreno". ${ }^{26}$

Con este despacho, Forniés se personó ante la Real Audencia para explicar que su representado "ha exercido y exerze la facultad de alarife con barios maestros" desde hacía veinticinco años y había intervenido "en barias obras que han ocurrido de quatorze años a esta parte en que dicha mi parte tomo el santo abito". Entre estas últimas citó explícitamente su participación en la construcción del convento y colegio de carmelitas de la Encarnación de Zaragoza, en otros cenobios de la Provincia sin especificar cuáles, y en la reedificación del Palacio Episcopal de Albarracín (Teruel). Además, reseñó que dichas fábricas, algunas todavía en ejecución en aquellos momentos, se habían llevado a cabo siempre con la complacencia de los comitentes, es decir, que en ningún caso habían existido daños ni inconvenientes en ellas. Por todo lo anterior, demandaba que su cliente fuera examinado para poder acceder al grado de maestro alarife de la ciudad de Zaragoza para lo que, como había tratado de demostrar, se encontraba plenamente apto.

El teniente primero de corregidor Moreno y Ortega atendió la solicitud y requirió a los mayordomos del gremio zaragozano de maestros de obras que, en el plazo de cuatro días, o bien admitiera a examen al religioso o bien expusiera las razones que justificaran el no hacerlo. Inmediatamente después, el notario Francisco de Alteza se encargó de notificar a Juan Yarza, mayordomo mayor de dicha corporación, todo lo expuesto.

Los albañiles actuaron con rapidez. Al día siguiente el gremio y cofradía de albañiles se reunió en la sala dispuesta al efecto en el convento de San Francisco. A la sesión acudieron: Juan Yarza, mayordomo mayor; Manuel de Sanclemente, veedor mayor; Blas Jiménez, veedor menor; Diego Amesti

\footnotetext{
25 Ibidem, ff. 6-10 v.

${ }^{26}$ Archivo Histórico Provincial de Zaragoza [A.H.Prov.Z.], Signatura J/012511/13.
} 
y Manuel Ceballos, consejeros mayor y menor respectivamente; José Yarza, luminero; Pedro Sánchez, secretario; Juan Sánchez, Miguel de Velasco, Tomás Ruiz, Francisco Velasco, Valero Blasco, Roque Muriel, José Estorguía, Agustín Escolano, Tomás Lizalde, Tomás Cortés, Vicente Ricarte, Manuel Monge y Francisco Pontón. Todo ellos designaron a Juan José Pérez de Hecho, Valero del Plano, Eugenio Bailín y José Forcada, notarios causídicos de Zaragoza, como sus representantes "en los pleitos cibiles y criminales" que esperaban.

Fue el primero de los procuradores citados, Juan José Pérez de Hecho, quien el 11 de julio acudió a la Real Audiencia para presentar las razones por las que sus principales no tenían intención de permitir a fray José Alberto Pina ni realizar el examen del gremio ni ejercer el oficio de alarife en la ciudad de Zaragoza. En primer lugar, los oficiales adujeron que, por su condición de religioso, Pina no podía cumplir las normas del gremio "con el rigor que permiten dichas ordinaciones y vaxo las penas en ellas estatuidas, ni se le puede compeler a su satisfaccion y cumplimiento". A esta circunstancia añadieron que la licencia que el fraile había obtenido de su superior no era suficiente para contemplar las ordenanzas del oficio debido a que, en virtud de su voto de obediencia, podía ordenarle hacer todo lo contrario. Además, aseguraron que el carmelita no poseía los doce años de práctica "que indispensablemente deve tener en casa de maestro alarife para poder ser admitido a examen", según estipulaban las ordinaciones del gremio, en concreto las ya mencionadas 6 y 18 . En consecuencia, "mientras no justifique haver tenido dichos doce años de practica de la manera prevenida", no sería posible permitirle la realización del examen. Redundando en esta cuestión, los cofrades valoraron el grave perjuicio que la admisión en el gremio tanto de Pina como de otros religiosos supondría para sus intereses, pues tomarían las "obras mas prinzipales, pribando" de ellas a los maestros que, "cargados de obligaciones sirben a su Magestad y a la ciudad" en virtud de "contribuziones", "de lo que se escusaria" a fray José Alberto "por su inmunidad".

Recibida la respuesta, el 18 de julio José Forniés, en nombre del carmelita, reiteró por escrito que a su representado se le debía admitir para la ejecución del examen porque cumplía todos los requisitos recogidos en las ordenanzas, incluidos los doce años de práctica que se ofreció a justificar debidamente, y que su condición de religioso no le impedía en absoluto desempeñar su oficio, reconociendo que si alguno de sus superiores le inhibiera para "trabajar, les quedaria expedito a los de dicho gremio". A todo ello quiso agregar su reflexión sobre la forma de averiguar la capacidad y la destreza de un alarife, más allá de la práctica del oficio durante doce años, "pues con ellos puede dexar de ser habil y sin ellos serlo, con que solo pueden servir para pidir examen, pero no para convenzer la idoneydad", y es en el examen "donde ha de constar de la pericia e idoneydad del pretendiente, a quien no hallandole suficiente y venemerito se devera excluir, pero no antes".

Además, no quiso pasar por alto la acusación de que los religiosos no pagaban impuestos pues, si bien "no vajo este nombre de contribucion, si vajo el de subsidio y escusado, e igualmente sirven sus individuos a su Magestad y a esta ciudad". Seguidamente, manifestó que no era su intención inmiscuirse en obras que no pertenecieran a su Orden sino solo en "los fundos y casas que son propios y pequliares de su religion, ni esta se le permitiria", lo que no obstaba para que fuera muy "digno de reparo" el que los carmelitas calzados pudieran contar con "un sugeto dentro de su comunidad habil para tratar y cuydar del reparo y manutencion de sus propias casas", a lo que el gremio intentaba oponerse. Ante esto, declaró que, como los maestros de obras zaragozanos no podían impedir que Pina "fabrique y travage en las casas arriba dichas", únicamente les restaba, según él, "estorvarlo, inhavilitando y apenando a los manzevos y aprehendizes de [los] que necesariamente se ha de ayudar para practicar semejantes fabricas".

A finales de mes, el gremio de maestros de obras, a través de Pérez de Hecho, solicitó a la justicia la desestimación de la causa y la condena al pago de las costas del proceso a la parte contraria. Igualmente, manifestó que los fueros y leyes del Reino de Aragón no permitían admitir a ningún artesano a examen de su oficio sin poseer la práctica y el resto de requisitos recogidos en las ordenanzas del gremio. Insistió en que fray José Alberto Pina únicamente había "estado en casa de maestro alarife de aprehendiz y añero" unos seis años desde donde "salio y se puso religioso siendo de muy poca edad, asi quando entro a ser aprendiz como quando salio a ponerse religioso". Además, aseguraron que la práctica en el arte de la albañilería que el carmelita pudo desempeñar en su Orden se limitó a intervenciones en su convento o en "los fundos de este", que en absoluto podían complementar los doce años requeridos por el gremio.

Inmediatamente después, rebatió incluso el argumento de Pina acerca de la idoneidad de un alba- 
ñil defendiendo que, aunque el que pretende examinarse poseyera la pericia en el oficio "y suficiencia necesaria como arquitecto", no era bastante para admitir su examen. A esto añadió que sus principales conocían casos que aun con la práctica concluida "no se les puede fiar una obra", de manera que, con la mitad de la praxis, no podían permitir su ingreso en el gremio. Asimismo, Pérez de Hecho recriminó al religioso que se sirviese de mancebos para el trabajo de albañilería en su convento dado que "compete a los maestros el drecho de no permitir que mancebo alguno que dependen de los maestros vaia a trabajar con ninguno que no sea maestro, y del uso de este drecho no se infiere lo que la otra parte supone". En ese sentido, recordó que, aunque todas las comunidades religiosas contaban con un maestro alarife para sus construcciones, cuando los superiores de las diferentes órdenes requerían la ayuda de algunos oficiales, "el tal maestro se los ha franqueado y les ha mandado fueran a trabajar sin interes alguno, de lo que resulta no ponersele directa ni indirectamente embarazo a la otra parte para trabajar por si en qualesquiere fabricas de su combento y fundos de este, pues en caso de necesitar de mas mancebos, con pidirlos al maestro que tiene dicha comunidad se los franquea".

Ante ello, el 3 de agosto el procurador de Pina respondió que, según las leyes aragonesas, la solicitud de examinarse para acceder al grado de maestro en cualquier gremio no prescribía, a lo que añadió que, incluso si lo requería cualquier persona extranjera, no se le exigía precisar ni hacer constar su aprendizaje ni sus años de práctica. Al mismo tiempo, recordaba que el gremio de albañiles de Zaragoza reconocía el aprendizaje y el oficialato por tiempo de seis años de su representado, ofreciéndose a justificar que el carmelita había ejercido el arte de la albañilería por espacio de muchos más años. Igualmente, protestaba porque la parte contraria parecía querer excluir a Pina por ser religioso, particularidad que no se contemplaba en las ordenanzas del gremio.

A continuación, Forniés quiso aclarar que cuando las comunidades religiosas contaban con un maestro alarife designado para la construcción de sus cenobios era en los casos que no existiera "religioso perito que pueda exercitarse en las fabricas pertenecientes asi a esta facultad como a qualquiera otra, y lo contrario dize bastante resistencia para creherla". Continuó con su razonamiento denunciando que su representado estaba siendo repudiado y que no demandaba ser calificado directamente como maestro, sino solo ser examinado. Además, concluía recordando que su caso no era en absoluto extraordinario pues era de dominio público que se había admitido a varios sujetos para realizar el examen para acceder a distintos gremios de la ciudad "sin calidad, prerrequisito ni practica correspondiente".

La respuesta de la corporación se hizo esperar hasta el 30 de agosto cuando, mediante su procurador Pérez de Hecho, recalcó una vez más el hecho de que, aunque le permitieran realizar el examen e incluso lo aprobara, fray José Alberto era "repugnante y quasi incapaz con su estado" de religioso. Seguidamente, rebatió el argumento relativo al fuero utilizado por la parte contraria explicando que su disposición se refería únicamente a los oficios mecánicos, "pero no de la arquitectura civil y militar, arte liberal, que es de la que ussan y exercen dichos mis partes, siendo la conserbacion de esta y su perizia mas importante". Además, el gremio negaba los años en los que Pina había trabajado como albañil en su propio convento por no hacerlo al amparo de un maestro aprobado "y en la casa y compañia de este". Pérez de Hecho finalizó su réplica manifestando que cuando habían sido necesarios mancebos u oficiales extra para la realización de obras en un cenobio "se les han buscado y permitido sin estipendio alguno ni utilidad propia" e incluso con descuento en su salario, pues cualquier particular debía pagar 4 reales de plata por día -3 para el mancebo y 1 para el maestro-, mientras que los religiosos desembolsaban únicamente 3 reales.

Para el 20 de septiembre el procurador del carmelita ya tenía su contestación preparada. En ella acusó de libre y torticera la interpretación del fuero aragonés por el gremio de alarifes e insistió en la idoneidad de su representado que nadie, "ni la parte contraria, con fundamento, podra negarla".

A continuación, Forniés solicitó una prórroga de quince días del periodo de prueba, a punto de finalizar, para poder continuar con las diligencias probatorias. El 25 de septiembre obtuvo el aplazamiento que fue notificado a ambas partes. El representante de fray José Alberto Pina aprovechó el nuevo plazo para requerir a los contrarios la presentación del libro del gremio de alarifes donde se anotaban los nombres de los nuevos maestros, así como el de los carpinteros y escultores de la ciudad. El 16 de octubre el teniente primero de corregidor atendió la demanda y ordenó a los secretarios de ambas corporaciones zaragozanas la exposición de dichos volúmenes en el plazo de tres días. Ante ello, Juan José Pérez de Hecho suplicó otra prórroga, que fue aprobada, pero no mostró los libros del gremio. El 7 de no- 
viembre, después de un nuevo requerimiento por parte de Pina, Moreno y Ortega exigió que dichos documentos fueran expuestos. Ese mismo día Martín de Villa y Pedro Sánchez, secretarios del gremio de escultores y albañiles, respectivamente, pusieron a disposición de la autoridad competente ambos ejemplares.

Pocos días después, el 12 de noviembre, tras tener la oportunidad de revisar los dos libros, Forniés, en primer lugar, reconoció que en el volumen del gremio de albañiles no había "cosa alguna de cuya compulsa necesitase". Sin embargo, en el de los carpinteros y escultores localizó una resolución de interés para el caso que fue inmediatamente transcrita y que, debido a su trascendencia para la causa, reproducimos aquí:

En 28 dias de octubre de 1691 el hermano Francisco Sierra, religioso del collegio de la Compañia de Jesus, pidio examen de [en]samblador a los señores mayordomos y demas oficiales nombrados con asistencia de Antonio Marco, andador de los señores jurados, y del dicho hermano Francisco Sierra, se le dispenso que no trazara ni hiciera pieza por tener noticia de su abilidad y pericia y assi en dicho dia quedo aplazado que dicho hermano no concierte obras de [en]samblaje ni carpinteria fuera del collegio en obras grandes, con esta condicion dio a la fabrica 15 libras. Pablo de Goya. Y para que conste lo firme en Zaragoza dicho dia, mes y año.

A continuación, se insertaron episodios similares acaecidos por las mismas fechas en otros gremios zaragozanos, previamente solicitados por fray José Alberto Pina a las distintas corporaciones de la ciudad. Así, primero, se recogió el caso de Sebastián Martínez, mancebo del oficio de carreteros, que en marzo de 1730 se vio en la obligación de reclamar ante la Real Audencia para que el gremio le permitiera realizar el examen correspondiente. Ante la negativa de la corporación, Fernando Moreno y Ortega decidió nombrar de oficio a Bernado Millán, maestro de hacer carros de la ciudad de Huesca, para que examinase al joven, prueba que este superó con suma habilidad. Este resultado capacitó al teniente primero de corregidor a declarar a Martínez maestro en fábricas de carretería de la ciudad de Zaragoza y sus barrios con facultad para "usar del mencionado oficio, habriendo botiga y trabajando publica y privadamente todo genero de piezas y cosas referentes a el". Sin embargo, el gremio interpuso una apelación solicitando al pos- tulante la realización de un yugo, instrumento que el joven debió confeccionar con total destreza, dando por concluida la causa. ${ }^{27}$

El segundo ejemplo fue el de Juan Conches, candidato a maestro tinturero de seda, iniciado en 1729 y conluido en octubre de 1731 con resultado también positivo para el demandante. ${ }^{28}$

Inmediatamente después se incluyó el testimonio de Manuel Recio, maestro en fabricar coches, que solicitó al gremio de torneros realizar su examen para acceder asimismo al grado de maestría en su oficio, aunque solo para poder confeccionar las piezas de tornería necesarias para un carruaje. Una vez abonadas las tasas de la prueba, Recio llevó a cabo el examen "con la calidad y limitaciones" exigidas, de tal modo que tuvo que crear dos pilastras de coche con sus basas y media caña y "sobre esta un medio bocelillo del qual nazca un jarron y sobre el por remate un medio bocel con sus dos quadrados y una media caña sobre el jarron con un medio bocel donde arranca el orinal con su capitel y sobre este su medio caña y plinto y encima por remate sus bolas", así como dos cubos de ruedas "de las de escopeadura adelante con un quarto bocel con su media caña y su bocal con dos quadrados", que el candidato presentó. El gremio declaró que las obras estaban realizadas "bien y conforme arte", por lo que admitieron a Recio como maestro tornero "para que pueda hacer y construir todas las piezas de torneria necesarias y que pide la construccion de coches y no otra ni mas ni en otra manera".

El siguiente caso aludido, en esta ocasión a petición del gremio de albañiles, requiere de mayor detenimiento pues su resolución influyó de modo directo en el que nos ocupa. Justamente el año anterior, en abril de 1730, Juan Yarza, mayordomo de bolsa de la cofradía del gremio, se negó a examinar a Andrés de Velasco porque no cumplía la ordenanza número 6 del oficio, es decir, la que estipulaba que, tras el periodo de aprendizaje ligado a un maestro durante cuatro años, el joven tenía que haber cubierto los ocho años de mancebía exigidos. Concluido este plazo, el postulante debía superar el examen, regulado en la ordinación número 7. Pese a que el resto de miembros de la corporación trataron de convencer a Yarza de que esta era una práctica habitual con los hijos de maestros del gremio y Velasco lo era, el mayordomo elevó la apelación a la Real Audencia. ${ }^{29}$ Esta falló a

\footnotetext{
27 Esta apelación puede ser consultada en A.H.Prov.Z., Signatura J/010006/13.

28 Este pleito se encuentra en A.H.Prov.Z., Signatura J/010937/10.

${ }^{29}$ Conservada en A.H.Prov.Z., Signatura J/014648/2.
} 
favor de la mayoría de miembros del gremio para que se pudiera examinar al mancebo, pero ordenó que "en adelante se obserbe rigurosamente la ordenanza sexta presentada igualmente con forasteros y con hijos de maestros sin dispensacion de tiempo". Sin embargo, en el transcurso del pleito, el oficial albañil zaragozano Marco Tarazona se personó ante el corregidor para suplicar que no solo se dispensara a Velasco de cumplir lo dispuesto en la ordinación, sino que se aplicara a todos en adelante, pues a él mismo solo le restaban dos años para concluir su periodo de mancebía y ya se encontraba capacitado para superar el examen. Además, recordó que él también había sido hijo de maestro albañil y que su madre, viuda y con otros hermanos menores de edad a su cargo, no disponía de otro sustento que el suyo. Como veremos enseguida, inmediatamente después Tarazona efectuó su examen y obtuvo la maestría.

Tras ello, con fecha 22 de diciembre, una vez concluido el periodo de prueba, José Forniés solicitó la publicación de probanzas con la intención de conocer qué es lo que la otra parte había justificado por medio de testigos, instrumentos o cualquier otro tipo de manifestaciones. En efecto, el gremio de maestros alarifes había preparado un interrogatorio compuesto por seis preguntas que formuló a tres personas: por la primera cuestión quería saber si el interpelado tenía conocimiento del pleito; la segunda se refería a que si era consciente de que dicho gremio se regía mediante estatutos y ordinaciones que debían observar tanto los maestros que practicaban ese oficio como los pretendientes a su ejercicio; la tercera era relativa al demandante sobre el que querían escrutar si había completado los doce años de aprendizaje y mancebía exigidos por el gremio o si, por el contrario, únicamente había cumplido seis años "en casa de maestros alarifes desde los quales salio a ponerse religioso"; por la cuarta querían averiguar si era cierto que fray José Alberto Pina había cometido varios errores durante los años que trabajó como albañil "en los fundos de su convento o religion" y si fue necesario reparar esos fallos para que la obra no se derrumbara; la quinta pregunta pretendía recabar información sobre la tan citada labor de los mancebos, en particular acerca de si los maestros les ordenaban trabajar en obras que no estuvieran dirigidas por ningún alarife examinado; y por la sexta y última querían conocer si las casas de religiosos contaban con la presencia de un maestro para controlar sus construcciones y si, "en caso de tener la comunidad algun religioso inteligente en todo genero de fabricas", se habían servido del maestro para que "este em- biara los manzebos necesarios para dichas fabricas [...] sin interes alguno, pagando a dichos manzebos tan solamente tres reales de plata por dia".

El primero de los testigos en responder a este cuestionario fue José Atarañosa, labrador, vecino de Zaragoza, de 33 años, el 26 de diciembre. A la primera pregunta contestó que conocía muy bien a las partes litigantes, aunque declaró no ser amigo ni familiar de ninguna de ellas. Ante la segunda explicó que sabía que el gremio de albañiles se gobernaba bajo sus propios estatutos y ordenanzas en todos los casos y que si estos no se cumplían ningún postulante podía acceder al grado de maestro ni trabajar en ninguna construcción. Pese a que desconocía lo requerido en la tercera, sí que manifestó ante la cuarta que había oído, "aunque no haze memoria a quien", que fray José Alberto Pina había construido "unas bodegas en la torre del combento de Nuestra señora del Carmen de la regular obserbancia de esta ciudad", y que en poco tiempo se arruinaron "por defecto de su fabrica", siendo necesario su apuntalamiento con "muchas maderas". A la quinta pregunta indicó que si alguna vez los mancebos trabajaban en una obra sin maestro eran multados por el gremio. Sin embargo, aseguró ignorar la respuesta de la sexta.

El segundo testigo fue José Latienda, mancebo albañil de 48 años, también vecino de Zaragoza. Como el informador anterior, Latienda conocía a las partes, pero, según afirmó, no mantenía ningún tipo de relación con ellas. A la segunda pregunta declaró que el gremio al que pertenecía se basaba en sus ordenanzas en todo momento, incluido en el acceso a la maestría, cuestión que conocía perfectamente en su calidad de mancebo. Ante la tercera reveló que solo sabía que, antes de ingresar en religión, José Alberto Pina había permanecido en casa del maestro alarife Lamberto Tarazona durante seis años seguidos, aunque sin recordar "si de aprendiz u añero", y que de allí pasó a casa de la viuda del maestro albañil José Borgas por menos de un año, "en cuyo tiempo tomo el avito". Para contestar a la siguiente, aseguró constarle que Pina construyó unas bodegas en la torre de su convento, asistido por él mismo, y que pasados seis meses aproximadamente "se noto que unos pilares se hallaban sueltos al centro de dichas bodegas que dividian sus tramadas, se abrieron y aquebraron a causa de estar hechos de piedra pelada". Ante ello, recordó que el carpintero del cenobio y el propio mancebo apuntalaron con maderas la fábrica hasta que llegó de nuevo fray José Alberto, "que se hallaba fuera de esta ciudad, que corto los referidos pilares y los hizo de ladrillo, haviendo explicado, a presencia 
del testigo, que el motibo de no haverlos hecho desde el principio de dicho material fue por ahorrar al combento su coste".

Con respecto a la quinta pregunta, Latienda confirmó la imposibilidad que tenían los mancebos de participar en construcciones que no fueran dirigidas por maestros y reconoció que los que lo habían hecho en alguna ocasión fueron sancionados por el gremio. Para responder a la última pregunta, recordó que era habitual que los conventos, en especial el del Carmelo calzado, contaran con la presencia de un maestro para controlar sus construcciones y que, en el caso de que dispusieran de un religioso "inteligente en dichas fabricas", solían servirse de un maestro secular para proporcionar a la obra los mancebos necesarios "pagando tan solamente tres reales a dichos manzebos sin interes alguno en los maestros". Además, confesó que él mismo había participado de dicha forma en la construcción del convento de Nuestra Señora del Carmen "por espacio de quatro años en diversas temporadas de orden de Manuel Monje, ${ }^{30}$ la viuda de Tarazona y de Joseph Estorgia".

El último testigo fue José Tristán, asimismo mancebo albañil de Zaragoza, de 35 años. Igual que los anteriores, Tristán conocía el litigio y también a las partes, asegurando, en su calidad de oficial, que el gremio de alarifes de la ciudad se gobernaba bajo sus estatutos y sus ordenanzas en todas las circunstancias. Ante la tercera pregunta explicó que sabía, a través de terceras personas, que fray José Alberto Pina cumplió su aprendizaje en casa de la viuda de Lamberto Tarazona y que, "a poco tiempo que hazia de añero, tomo el avito". En relación a la siguiente cuestión, solo pudo decir que había oído contar tanto a José Latienda como a otras personas el suceso con los pilares de la bodega del convento del Carmen. La respuesta a la pregunta número cinco fue idéntica a la de los dos informadores anteriores, mientras que, ante la sexta, aseguró que era frecuente que los conventos de la ciudad se sirvieran de maestros del gremio de albañiles para la dirección de sus fábricas, pero que si algún cenobio contaba con un religioso "inteligente en dicho exercicio" se valían de dicho maestro para proporcionar mancebos a la edificación, reconociendo que él mismo había sido uno de ellos a las órdenes del maestro José
Estorguía cuando trabajó durante varias temporadas en la construcción del convento de carmelitas descalzos de San José.

Por su parte, el 12 de diciembre fray José Alberto llamó a declarar al ya mencionado Marco Tarazona, maestro de obras de Zaragoza. Marco explicó que el 29 de abril de ese mismo año de 1731 -en el contexto del mencionado pleito de Andrés de Velasco- solicitó a los mayordomos del gremio de albañiles la realización del examen. Ante ello, estos quisieron saber si cumplía las ordinaciones a lo que respondió que, aconsejado por el maestro de obras Tomás Ruiz, ${ }^{31}$ "lo dexaba a la prudencia de los señores de la junta, y que lo examinaron y quedo admitido por maestro de obras" con solo seis años de práctica.

A continuación, José Forniés, como se recordará procurador de Pina, reprobó y negó con contundencia el testimonio de José Latienda y José Tristán acerca de la fábrica arruinada de la bodega de la torre del convento de Nuestra Señora del Carmen supuestamente realizada por el religioso, asegurando que únicamente se pretendía desacreditar "la estimacion de mi parte y de su notoria pericia". A esto añadió que ambos testigos eran nulos por pertenecer al gremio y que, al parecer, Latienda era pariente del maestro José Estorguía, implicado en la causa como miembro de la corporación litigante.

Oídas las partes, el 5 de mayo de 1732 Fernando Moreno y Ortega dictaminó que, como el gremio de maestros de obras de la ciudad no había sido capaz de probar "sus excepciones", fray José Alberto Pina debía ser examinado en el plazo de ocho días y, "hallandolo havil e idoneo", sería admitido como maestro de obras con la condición de tener "facultad de entender como tal maestro en los combentos, casas y fundos de su religion y no en otros algunos". Asimismo, no condenó a costas a ninguna de las partes, sino únicamente a que cada una de ellas se encargara de cubrir las "por si causadas y las comunes por mitad".

Sin embargo, el gremio no quedó en absoluto conforme y una semana más tarde interpuso una apelación para anular la sentencia, a la que se unió como parte interesada en la causa la corporación municipal de Zaragoza. El 28 de mayo de

30 Hemos localizado a un maestro albañil llamado Pedro Monje, casado y con cuatro hijos -dos niños y dos niñas-, que en 1723 residía en una casa del capítulo del Portillo ubicada en la calle del Pabostre (BALLESTín MIGUEL, José Miguel, Zaragoza según el plano de 1712 y su vecindario de 1723. Zaragoza: Institución "Fernando el Católico", 2017, n 3.409, p. 239).

${ }^{31}$ Ruiz fue examinado en 1695, según se documenta en ALMERíA, José Antonio et al. Las artes en Zaragoza en el último tercio del siglo XVII (1676-1696). Estudio documental. Zaragoza: Institución "Fernando el Católico", 1983, p. 175. 
1732 el procurador Valero del Plano fue en esta ocasión el encargado de manifestar las razones de sus principales para resistirse a examinar a Pina. La primera de ellas seguía siendo su estado de religioso que le hacía inmune a la jurisdicción secular e incompatible a cualquier empleo laico, defendiendo que "aun quando ubiera sido maestro del gremio de mis partes, antes de entrar en religion, aviendo profesado en esta, quedaba fuera del gremio". Asimismo, aducía que, aunque los fueros de Aragón trataban de los exámenes de las distintas corporaciones, solo se referían a personas seglares y no religiosas.

En efecto, los fueros de 1684, que regirían estas cuestiones todavía en 1731, contemplaban los exámenes de los gremios, en concreto sus aspectos económicos, pero sin establecer ninguna distinción entre religiosos o civiles. Sin embargo, sí que estipulaba que "para aumentar la poblacion, y que aya mayor numero de oficiales [...], se ordena que si algun forastero huviere de ser examinado, aunque no pruebe aprendizaje, ni el aver sido oficial, se le admita a examen y constando de la pericia, no deva pagar mas de la mitad de lo que en dicho fuero de [16]78 se señala a los oficiales naturales. ${ }^{32} \mathrm{Y}$ que si alguno se huviere de examinar en oficio que corresponde a muchas fabricas y no supiere mas que alguna de ellas, se le examine en la que supiere pagando las dichas cantidades y no pudiendo trabajar en otra fabrica, que en la que estuviere examinado". ${ }^{33}$ De este modo, comprobamos que, como a continuación alegará Pina, los fueros de Aragón también le amparaban.

Por último, el procurador del gremio reconocía que "nada de lo dicho subsana la taxativa con que esta conzebida dicha sentencia", pues el mencionado fraile únicamente poseía facultad "de entender como tal maestro en los combentos, casas y fundos de su religion, lo uno porque sin estar examinado dicho fray Pina en su religion y respective los demas religiosos en las suyas, entienden y disponen en las obras y fabricas de sus combentos, casas y fundos, sin que mis partes les embarazen", y "lo otro porque en todos tiempos a havido y ay en las religiones ombres muy aviles en los exercicios y facultades de los gremios y las han exerzitado a utilidad de sus monasterios sin estar jamas examinados", además de que "no por su perizia han intentado se les diera examen en el gremio de la facultad en que se empleaban por ser esto repugnante a su estado". A esta perorata, del Plano añadió que, de ser admitido en el gremio un religioso, este debería ocupar los cargos del mismo, cuestión, en su opinión, del todo incompatible con su privilegiada condición. Según él, esta circunstancia conllevaría igualmente graves prejuicios al resto de miembros de la corporación, en concreto a los oficiales y a las viudas de maestros que dejarían de percibir la correspondiente cantidad ecónomica por ello. Para concluir su intervención, el procurador volvió a recordar que Pina, religioso o no, incumplía la tan mencionada ordinación número 6 del gremio.

La respuesta del carmelita a través de su representante José Forniés se hizo esperar hasta el 1 de julio. Sin duda exhausto, este se negó a renunciar a su derecho a examen pues, efectivamente, el fuero aragonés no diferenciaba entre postulantes seculares y religiosos, motivo por el cual no podía quedar excluido. Además, fray José Alberto exigía que su idoneidad en el arte de la albañilería "se apruebe o repruebe por los peritos", obviando "la inmunidad y exempcion de que goza". Consideró que la actuación del gremio era odiosa y denigrante, y que existían, como ya se vio, casos de religiosos examinados en distintas artes mecánicas. Censuró que fuera suficiente con decir, tal y como defendía la corporación, que tanto él como otros religiosos "sin el examen, entienden, y disponen en las obras y fabricas" sin ningún inconveniente, pues era falto a la verdad ya que no les permitían que ni mancebo ni aprendiz "les asista en semejantes obras, con lo que bajo de un pretexto honrado logran la inhivicion que apetecen". Asimismo, tildó de absurdos los gravámenes a la cofra-

\footnotetext{
32 Según los fueros de 1678, "por los daños que podría traer el trabajar sin la pericia suficiente al beneficio publico, se estatuye y ordena que se conserven los examenes en los gremios y oficios. Y porque el perjuizio mayor consiste en los excesivos gastos de estos examenes, se estatuye que de aqui adelante en la ciudad de Zaragoça en las cofadrias de los plateros, sederos, veleros, velluteros y tafetaneros, carpinteros, ensambladores y escultores, albañiles, confiteros, cereros, pasamaneros, pelayres, sastres, zapateros de obra nueva y texedores de lino y lana, los que se examinaren en los oficios de dichos gremios y cofadrias no puedan gastar ni dar mas que diez libras jaquesas para el cuerpo de la cofadria". En Fueros y actos de corte de el Reyno de Aragon hechos por la sacra, catolica y real magestad del rey don Carlos II, nuestro señor, en las Cortes convocadas en la ciudad de Calatayud, y prorrogadas a la de Zaragoça, y en ella fenecidas en los años de MDCLXXVII y MDCLXXVIII. Zaragoza: Pascual Bueno, 1678, f. 6 v.

33 Fueros y actos de corte del Reyno de Aragon hechos por la sacra, catolica y real magestad del rey don Carlos II, nuestro señor, en las Cortes convocadas en la ciudad de Zaragoça el dia diez y siete de marzo del año MDCLXXXIV. Zaragoza: Pascual Bueno, 1686, ff. 3-3 v. Como hemos podido comprobar y según expresa el profesor Guillermo Redondo, este fuero, pese a ser antigremial, amplió la facilidad para acceder a las corporaciones (REDONDO VEINTEMILLAS, Guillermo, 1982, p. 151).
} 
día mencionados dado que su exención le despojaría de cualquier materialidad. Por último, se lamentó de que este tipo de actuaciones no hacían más que privar a la sociedad de un mayor número de peritos que pudieran visurar las fábricas de la ciudad en construcción asegurando su calidad.

El 23 de julio Valero del Plano contestó reiterando y reforzando los argumentos anteriores, así como tildando de evidente contradicción y de acción repugnante el hecho de que el carmelita parecía únicamente demandar "un certificado" gratuito de su pericia en el arte de la albañilería. Ese mismo día Vicente Gascón, en nombre de la corporación municipal zaragozana, intervino en los autos de apelación para apoyar la revocación de la sentencia anterior y manifestar que la pretensión de Pina "es del todo turbativa del buen orden economico y politico" con los que la ciudad "tiene ordenados y distribuidos los gremios de sus artesanos mediante las ordenanzas", por su estado de religioso profeso. La municipalidad insistió en los graves inconvenientes que se seguirían tras su acceso a la maestría, "asi para los demas efectos y trascendencias de tal maestro para con obras y oficiales, como por el exemplar para con otras religiones y toda especie [de] indibiduos suyos que tubiesen alguna pericia en otros artes".

Una vez más, Forniés rebatió dichos razonamientos con contundencia alegando que, como quedó demostrado, otros religiosos habían obtenido el grado de maestro sin incurrir en ninguna "monstruosidad". Insistió en que la demanda de su representado no había sido interpuesta para gozar de ninguna facultad del gremio, salvo el poder trabajar con mancebos y oficiales a su cargo en las obras por él dirigidas.

Esta fue la última intervención por escrito recogida en el pleito. A estos argumentos no procedieron a contestar ni las autoridades municipales ni el gremio. Ante este silencio, Forniés se dirigió a la Real Audencia en repetidas ocasiones para demandar respuesta, pero no la obtuvo. La última está fechada el 11 de diciembre de 1733, día en el que se le concedió una nueva prórroga del periodo de prueba. No obstante, el 26 de mayo de 1735 se adjuntó, en folios sueltos, la tasación de las costas imputadas a cada una de las partes del pleito, de tal modo que el gremio de maestros de obras tuvo que pagar 33 reales 9 maravedíes, fray José Alberto Pina 50 reales 9 maravedíes, y la municipalidad 23 reales 9 maravedíes.

\section{El arquitecto fray José Alberto Pina (1693- 1772): nuevos datos biográficos a la luz de esta fuente}

Sabemos que fray José Alberto Pina nació en la localidad zaragozana de Moyuela en 1693. ${ }^{34}$ Según la documentación de su Orden, profesó en el Carmen calzado en Zaragoza el 16 de abril de 1719,35 y no en 1717 como apuntó su procurador en la causa aquí estudiada. Este aseguró que el fraile inició su carrera como alarife hacía veinticinco años a restar desde 1731, esto es, en 1706, de tal modo que contaba con 13 años de edad. De ser cierta esta información, consideramos que debió ser entonces cuando Pina convino su aprendizaje con el maestro de obras zaragozano Lamberto Tarazona, en cuya casa permaneció, a la luz de los datos revelados en este pleito, durante seis años. Tras este lapso de tiempo, suponemos que ya como mancebo, hacia 1712 se estableció con la viuda del maestro José Borgas únicamente por un año, según los testigos, de donde partió para tomar el hábito carmelitano.

Sin embargo, los cálculos no concuerdan dado que, por este recuento, José Alberto Pina debería haber ingresado en religión entre 1713 y 1714, mientras que su partida de profesión, como indicamos, certifica que lo hizo el 16 de abril de 1719 . Como quedó establecido en el Concilio de Trento -en la sesión XXV, cap. XV- ${ }^{36}$ todos los postulantes a ingresar en cualquier orden religiosa debían ser mayores de 16 años y llevar a cabo un año de noviciado antes de profesar, razón por la que, si hubieran sido ciertas estas fechas, Pina habría estado preparado para realizar su profesión para 17151716. Lamentablemente, de momento, no estamos capacitados para rellenar esta laguna.

Sabemos que el maestro de obras zaragozano Lamberto Tarazona residía en la calle de Predicadores, en el barrio de San Pablo, junto con su esposa, sus cuatro hijos, dos varones y dos féminas,

\footnotetext{
34 ORELLANA, Marcos Antonio de, Biblioteca Pictórica Valentina o Vida de los pintores, arquitectos, escultores y grabadores valencianos ( $2^{\mathrm{a}}$ ed. de Xavier de Salas). Valencia: Ayuntamiento de Valencia, 1967, p. 543.

35 Publicada en ABADÍA TIRADO, José, "Fray José Alberto Pina: El Arquitecto (1)". El Gallico de Moyuela, 79, 2013, p. 11.

${ }^{36}$ El Sacrosanto y Ecuménico Concilio de Trento traducido al idioma castellano por don Ignacio López de Ayala. Con el texto latino corregido según la edición auténtica de Roma publicada en 1564. Nueva edición aumentada con el Sumario de la historia del Concilio de Trento escrito por don Mariano Latre. Barcelona: Imprenta de Ramón Martín Indár, 1847, p. 372.
} 
y dos criados. ${ }^{37}$ Está documentada su participación en la construcción de la iglesia de Nuestra Señora del Portillo de Zaragoza a comienzos del siglo XVIII ${ }^{38}$ y la realización de la visura de la reforma de la iglesia parroquial de San Gil entre 1720 y $1725 .^{39}$ El 29 de septiembre de 1726, sintiéndose falto de salud, dictó sus últimas voluntades. En ellas manifestó su deseo de recibir sepelio en una de las sepulturas de la cofradía de Nuestra Señora del Pópulo en la parroquia de San Pablo, de la que era cofrade. Para entonces, reconoció ser padre, con su mujer Rosa Cebollero, de tres vástagos llamados Catalina, ${ }^{40}$ Marco y Juan Tarazona. ${ }^{41}$

Por su parte, José Borgas, el otro maestro de Pina, estuvo activo en Zaragoza entre el último cuarto del siglo XVII y el primero del XVIII. Ha sido reconocido como uno de los más reputados albañiles de la ciudad en aquellos momentos debido a la importancia de sus obras. De hecho, trabajó en las iglesias del convento de San Agustín en 1686 y de San Ildefonso entre 1692 y 1695, en esta última en compañía de Jaime Busiñac y Borbón; en 1696 se encargó de visurar, con Gaspar Serrano, la fábrica de la iglesia de Santa Isabel; y en 1702 trazó el templo de Nuestra Señora del Portillo, también junto con Gaspar Serrano de cuya construcción se tuvo que hacer cargo en solitario tras el fallecimiento de este. ${ }^{42}$ En julio de 1722 Borgas, "enfermo de accidentes avituales, pero sin hazer cama", y su esposa Ana María Atolín, "con perfecta salud", otorgaron su testamento. Ambos mostraron su intención de ser enterrados en la iglesia del convento de San Francisco con el hábito de la Orden. Declararon ser padres de Bartolomé Borgas, Clara Borgas mujer de Manuel Casalvón, y de sor Ana María Borgas, religiosa franciscana del cenobio de Santa Catalina de Zaragoza. Asimismo, en el documento nombraron a sus nietos Vicente José, María Antonia y Bruno Borgas, hijos de Bartolomé y de su esposa Catalina Arenas. ${ }^{43}$

Además, como vimos, el pleito analizado reveló también que fray José Alberto había participado tanto en la edificación del convento de carmelitas de la Encarnación de Zaragoza como en la de otros cenobios de la Provincia, aunque sin especificar cuáles, y en la reedificación del Palacio Episcopal de Albarracín. En efecto, su intervención en el patrimonio albarracinense era conocida. Fue a instancias del obispo Juan Francisco Navarro Salvador y Gilaberte (1727-1765) quien decidió emprender las obras necesarias para redistribuir y acondicionar el inmueble, para entonces en estado indecoroso. Al parecer, la reforma, que otorgó al edificio el aspecto con el que ha llegado a nuestros días, fue enjundiosa y estuvo dirigida por Pina. ${ }^{44}$ Es muy probable que a él también se deba el diseño de la portada principal en la que campea el escudo del prelado comitente. Posiblemente al mismo tiempo trabajó en el convento que su Orden mantenía en Gea de Albarracín. ${ }^{45}$

Sin embargo, se ignoraba ${ }^{46}$ su labor en el convento de las madres carmelitas de Zaragoza dedicado a la Encarnación, emplazado junto a la Puerta del Carmen, pues el cenobio que ha llegado a nuestros dí-

37 BALLESTín MIGUEL, José Miguel, 2017, n 1.442, p. 190.

38 SÁNCHEZ MARTíNEZ, Concepción, Estudio histórico-artístico de la Iglesia de Nuestra Señora del Portillo de Zaragoza. Zaragoza: Institución "Fernando el Católico", 1983, p. 23.

${ }^{39}$ GARCÍA DE PASO REMÓN, Alfonso, La Iglesia Parroquial de San Gil Abad de Zaragoza. Zaragoza: Institución "Fernando el Católico", 1985, p. 22.

40 En junio de 1722 Catalina contrajo matrimonio con Francisco Molina y Tirao, maestro carpintero, hijo de Juan Molina y Tirao y de la difunta María Sopena, vecinos de Zaragoza (Archivo Histórico de Protocolos Notariales de Zaragoza [A.H.P.Z.] Braulio Villanueva, 1722, $n^{\circ} 4568$, f. 325 v.-328) (Zaragoza, 28-Vl-1722).

${ }^{41}$ A.H.P.Z., Braulio Villanueva, 1726, n 4570, ff. 509-510 (Zaragoza, 29-IX-1726).

${ }^{42}$ SÁNCHEZ MARTíNEZ, Concepción, 1983, p. 21 y doc. n 14, p. 94; ALMERÍA, José Antonio et al., 1983, pp. 84-85 y 142-143; BRUÑÉN IBÁÑEZ, Ana Isabel; CALVO COMÍN, Ma Luisa y SENAC RUBIO, Ma Begoña, Las artes en Zaragoza en el tercer cuarto del siglo XVII (1655-1675). Estudio documental. Zaragoza: Institución "Fernando el Católico", 1987, pp. 88-89; y MARTíNEZ VERÓN, Jesús, Arquitectos en Aragón. Diccionario histórico, 5 vols. Zaragoza: Institución "Fernando el Católico", 2000, vol. I, pp. 78-79. Disponible en línea en https://ifc.dpz.es/recursos/publicaciones/22/15/ebook2109.pdf (fecha de consulta: 30/07/ 2017).

${ }^{43}$ A.H.P.Z., Juan Isidoro Andrés, 1722, n 4859, ff. 308-309 v. (Zaragoza, ¿20?-VII-1722).

${ }^{44}$ ALMAGRO GORBEA, Antonio y ARCE OLIVA, Ernesto, Palacio Episcopal de Albarracín. Zaragoza: Fundación Santa María de Albarracín, 2011, p. 41.

45 LÓPEZ-MELUS, Rafael Ma, VII Centenario del Carmelo de Zaragoza. Zaragoza: Amacar, 1991, pp. 191-192.

${ }^{46}$ Es posible que López-Melus se refiera a este templo cuando asegura que Pina diseñó la iglesia del convento del Carmen calzado de Zaragoza pues no diferencia si se trata del de la rama masculina, dedicado a San José, o el de la femenina, bajo la advocación de la Encarnación. En idem. 
as fue levantado ex novo en el siglo $\mathrm{XX} .{ }^{47} \mathrm{El}$ cometido de fray José Alberto en esta clausura tuvo que ceñirse a la iglesia dado que tenemos constancia de que el 18 de octubre de 1724 los religiosos del convento de carmelitas calzados de San José -situado justo enfrente del femenino- solicitaron autorización a la parroquia de San Pablo para procesionar por las calles del barrio con motivo del traslado del Santísimo Sacramento "a la iglesia que nuebamente se ha construido y fabricado para el convento de religiosas de Nuestra Señora del Carmen bajo el titulo de la Encarnacion". ${ }^{48}$ De este inmueble solo nos han llegado algunas imágenes retrospectivas en las que se aprecia levemente el edificio ubicado detrás de la célebre Puerta del Carmen, otras de su demolición, y su retablo mayor, conservado en la parroquia del Pilar de Bilbao adonde llegó a finales de la década de 1960 gracias a la acción de su párroco y de los hermanos Albareda que se encargaron de transformar su aspecto original. El mueble fue financiado por Manuel Pérez de Araciel y Rada, arzobispo de Zaragoza entre 1714 y 1726, quien contribuyó también, junto con el legado de 1704 del notario José Pérez de Oviedo, a sufragar la construcción del templo. ${ }^{49}$

Gracias al padre Faci sabemos que la fábrica de la nueva iglesia fue capitulada el 27 de mayo de 1704 con los maestros de obras José Estorguía ${ }^{50}$ y José Ruiz. Para finales de agosto la edificación ya había comenzado, pero la guerra de Sucesión afectó tanto económica como políticamente a Pérez de Oviedo, partidario del archiduque Carlos de Austria. A esta circunstancia se unió su fallecimiento en 1707, de manera que la construcción del templo conventual tuvo que ser paralizada. De este modo prosiguió hasta 1723, año en el que el arzobispo Pérez de Araciel decidió costear su conclusión.

El templo, demolido en 1961 por motivos urbanísticos, era de reducidas dimensiones, contaba con una sola nave con transepto destacado en planta dotado de capillas abiertas en sus brazos y cabecera de testero recto flanqueada por el coro bajo y la sacristía. El crucero se cubría con una cúpula sobre pechinas en las que campeaba la heráldica del arzobispo Pérez de Araciel. Asimismo, disponía de coro alto a los pies. ${ }^{51}$

Como avanzamos, la iglesia fue terminada en octubre de 1724. Aunque desconocemos con total seguridad qué albañil pudo hacerse cargo de culminarla pues para entonces José Estorguía ya había fallecido, ${ }^{52}$ fue en esta fase en la que debió participar fray José Alberto Pina. Es posible que él fuera el alarife que dirigió la fábrica y que esta constituyera una de esas ocasiones en las que se encontró con problemas a la hora de contratar oficiales que le asistieran debido a no poseer el rango de maestro examinado por el gremio, tal y como se destacó en la causa analizada.

Asimismo, consideramos como muy probable que en el transcurso del pleito, ante el cariz que este estaba tomando, fray José Alberto solicitara a sus superiores el traslado a otro convento, pues está documentada su presencia como residente en el cenobio carmelita de Tudela (Navarra) entre 1732 y 1735 aproximadamente. ${ }^{53}$ A partir de entonces, el religioso recorrió parte de la geografía aragonesa y navarra, pero sobre todo la antigua demarcación territorial de la diócesis de Tarazona dejando su huella arquitectónica. La primera obra de la que se tiene constancia data de 1732 cuando debió diseñar la iglesia del convento de la Compañía de María de Tudela de planta centralizada. ${ }^{54}$ El siguiente fue un año de gran actividad para el fraile pues sabemos que en 1733 visuró la torre de la parroquial de Cascante (Navarra) que Juan de Estanga estaba construyendo, pero que había sido delineada por el propio fraile en compañía del

47 ANSÓN NAVARRO, Arturo, El entorno del Convento del Carmen de Zaragoza. Una reconstrucción histórica y artística. Siglos XIII al XX. Zaragoza: Elazar Ediciones, 2007, pp. 209-249.

48 A.H.P.Z., Braulio Villanueva, 1724, nº 4569, ff. 541 v.-543 (Zaragoza, 18-X-1724).

49 LÓPEZ-MELUS, Rafael Maa, 1991, pp. 104-105; VELASCO BAYÓN, Balbino, Historia del Carmelo español, 3 vols. Roma: Edizioni Carmelitane, 1992, vol. II, p. 633; ZORROZUA SANTISTEBAN, Julen, "Un retablo barroco procedente de Zaragoza en la iglesia bilbaína del Pilar". Artigrama, 18, 2003, pp. 435-438; y ANSÓN NAVARRO, Arturo, 2007, pp. 229-231.

${ }^{50}$ Acerca de este albañil consúltese MARTíNEZ VERÓN, Jesús, 2001, vol. II, pp. 155-156. Disponible en línea en https://ifc.dpz.es/ recursos/publicaciones/22/15/ebook2109_2.pdf (fecha de consulta: 01/08/2017).

${ }^{51}$ ANSÓN NAVARRO, Arturo, 2007, pp. 228-229.

52 En un acto notarial de comienzos de febrero de 1722 se cita a José Estorguía, maestro de obras, y a su hermana Lucía Estorguía, esposa de Francisco Martín, ambos son hijos de José Estorguía, ya difunto, y de Teresa Arilla (A.H.P.Z., Juan Isidoro Andrés, 1722, n 4859, ff. 54-54 v. [¿?]) (Zaragoza, 4-II-1722). El profesor Ansón considera que pudo ser el hijo homónimo de Estorguía quien se encargó de continuar los trabajos en el convento carmelitano (ANSÓN NAVARRO, Arturo, 2007, pp. 227-228).

53 AZANZA LÓPEZ, José Javier, 1998 a, p. 12.

${ }^{54}$ Ibidem, pp. 15-17. 
maestro de obras tudelano Juan Antonio Marzal:55 trazó la iglesia de Santiago y San Miguel de Luna (Zaragoza), ${ }^{56}$ de planta de salón; $y$, a partir de entonces, intervino, junto con Juan Antonio Marzal, en la inspección de la fábrica de la nave de la parroquia de Santa Eufemia de Villafranca (Navarra), construida por José de Arizmendi, así como en la traza de la nueva cúpula ideada por ambos. ${ }^{57} \mathrm{En}$ 1733 fue el encargado de trazar el pórtico de la catedral de Nuestra Señora de la Huerta de Tarazona (Zaragoza) y supervisar su construcción hasta $1737,{ }^{58}$ ejecutada por el cantero Juan de Estanga y el maestro de obras turiasonense José Sánchez. ${ }^{59}$

En 1735 está documentada su presencia en Ateca (Zaragoza), población perteneciente a la diócesis turiasonense, elaborando un informe sobre la continuación de las obras de la iglesia parroquial. ${ }^{60}$

Su nombre también se asocia con la sacristía de la iglesia de San Jorge el Real, antiguo colegio de la Compañía de Jesús de Tudela, fruto de una refor- ma llevada a cabo en la década de 1730, ejecutada con una solución muy similar a la empleada en la Compañía de María. Lo mismo sucede con la cúpula de la iglesia del convento de capuchinas de la ciudad ribera, de mediados del siglo XVIII, que muestra evidentes analogías arquitectónicas con las obras anteriores. ${ }^{61}$ Asimismo, se le atribuye la interesante ermita de San Clemente de Moyuela, su localidad natal, ${ }^{62}$ y la sacristía de la colegiata de Santa María de Calatayud que Pina pudo diseñar hacia $1735 .^{63}$ De igual modo, es posible que se debieran a este carmelita la traza de la cúpula y la torre de la iglesia del colegio de la Compañía de Jesús y la iglesia de San Atilano, ambas construcciones en Tarazona. ${ }^{64}$

Marcos Antonio de Orellana recoge que fray José Alberto Pina, solo en Aragón, "según se le oyó decir varias veces, construyó 24 iglesias, siendo otra de ellas la de Exea", ${ }^{65}$ que quizá haga referencia a la de la Virgen de la Oliva de Ejea de los Caballeros (Zaragoza), el único de los tres templos de la locali-

55 Ibidem, p. 15

56 EXPÓSITO SEBASTIÁN, Manuel. "Precisiones sobre la construcción durante el siglo XVIII, de la iglesia parroquial de Luna (Zaragoza)". Suessetania, 12, 1992, pp. 81-98, esp. p. 84.

57 AZANZA LÓPEZ, José Javier, 1998 a, p. 12; y AZANZA LÓPEZ, José Javier, Arquitectura y religiosidad barrocas en Villafranca (Navarra). Villafranca: Parroquia de Santa Eufemia de Villafranca y Departamento de Historia del Arte de la Universidad de Navarra, 1999, pp. 66-70.

58 La presencia de fray José Alberto Pina en Tarazona para reconocer la construcción del pórtico está documentada el 20 de julio de 1734, el 1 de noviembre de 1734, el 28 de agosto de 1735, en noviembre del mismo año e incluso el 16 de mayo de 1737 (Archivo de la Catedral de Tarazona, Caja 242, Libro de la Primicia de la Santa Iglesia de Tarazona [1715-1761], ff. 159 v. 160, 164 v., 165 y 175 v., respectivamente).

59 Archivo Histórico de Protocolos Notariales de Tarazona, Rafael Sánchez, 1733, ff. 183-183v (Tarazona, 6-XI-1733). Documento citado en ESCRIBANO SÁNCHEZ, José Carlos, "El pórtico de la Catedral de Tarazona". Hydria, 2, 1997, pp. 10-11; y en GÓMEZ URDÁÑEZ, Carmen, "La 'puerta mayor' de la catedral de Tarazona. Del siglo XIII al siglo XX". En RAMALLO ASENSIO, G. A. (coord.), Las catedrales españolas del Barroco a los Historicismos. Murcia: Universidad de Murcia y Gobierno de la Región de Murcia, 2003, pp. 343-345. Véase asimismo CARRETERO CALVO, Rebeca y ANSÓN NAVARRO, Arturo, "La Catedral de Tarazona en los siglos del Barroco". En: La catedral de Santa María de la Huerta de Tarazona. Zaragoza: Diputación Provincial de Zaragoza, 2013, pp. 195-198; y CARRETERO CALVO, Rebeca, “La catedral de Tarazona en el siglo XVIII: Renovación artística y transformaciones arquitectónicas". Tvriaso, XXIII, 2016-2017, pp. 9-52, esp. doc. n² 2, pp. 43-48.

60 MARTíNEZ VERÓN, Jesús, 2001, vol. III, p. 366. Disponible en línea en https://ifc.dpz.es/recursos/publicaciones/22/15/ebook2109_3.pdf (fecha de consulta: 01/08/2017).

61 ECHEVERRÍA GOÑI, Pedro Luis y FERNÁNDEZ GRACIA, Ricardo, "Arquitectura religiosa de los siglos XVI al XVIII en Navarra". En: Ibaiak eta Haranak, Guía del patrimonio histórico-artístico-paisajístico, 10 vols. San Sebastián: Etor, vol. 8, 1991, p. 204 AZANZA LÓPEZ, José Javier, Arquitectura religiosa del barroco en Navarra. Pamplona: Gobierno de Navarra, 1998 b, pp. 304 305; y FERNÁNDEZ GRACIA, Ricardo, El retablo barroco en Navarra. Pamplona: Gobierno de Navarra, 2003, pp. 421-423.

Las relaciones entre estos tres edificios ya fueron señaladas en GARCíA GAINZA, Ma Concepción (dir.), Catálogo monumental de Navarra, I. Merindad de Tudela. Pamplona: Institución Príncipe de Viana, Arzobispado de Pamplona y Universidad de Navarra, 2003 (1 ${ }^{\text {a }}$ reimp.; $1^{\text {a }}$ ed. de 1980), pp. 315-316 [sacristía de la parroquia de San Jorge], pp. 340-343 [iglesia de la Compañía de María], y pp. 346-347 [iglesia del convento de capuchinas]; y en AZANZA LÓPEZ, José Javier, 1998 b, pp. $354-355$.

62 CARRERAS ASENSIO, José $\mathrm{M}^{\mathrm{a}}$, "Ermitas barrocas de planta de cruz griega, cúpula y brazos semicirculares en el área de Daroca". Xiloca, 32, 2004, p. 45.

63 CARRETERO CALVO, Rebeca, "El arquitecto fray José Alberto Pina y la sacristía de la Colegiata de Santa María de Calatayud". En: IX Encuentro de Estudios Bilbilitanos. 2 vols. Calatayud: Centro de Estudios Bilbilitanos, 2016, vol. II, pp. 767-782.

64 CARRETERO CALVO, Rebeca, "La iglesia de San Atilano construida sobre su casa natal". En: CARRETERO CALVO, R. y CRIADO MAINAR, J. (coords.), MILENIO. San Atilano y Tarazona (1009-2009). Tarazona: Fundación Tarazona Monumental, 2009 pp. 111-133; y CARRETERO CALVO, Rebeca, Arte y arquitectura conventual en Tarazona en los siglos XVII y XVIII. Tarazona: Centro de Estudios Turiasonenses y Fundación Tarazona Monumental, 2012, pp. 185-186.

65 ORELLANA, Marcos Antonio de, 1967, p. 544. 
dad que fue construido en el siglo XVIII. No obstante, Expósito Sebastián consideró que se trataba de un número demasiado elevado para que fueran únicamente obras proyectadas por el carmelita, de manera que en él se debían englobar también las fábricas que dirigió o visuró a lo largo de su vida en tierras aragonesas. ${ }^{66}$ Sin embargo, en este sentido es interesante destacar que fray Antonio de San José Pontones, un arquitecto jerónimo coetáneo a él y bien estudiado, trabajó a lo largo de su vida en ciento setenta y dos edificios con más de cincuenta trazas documentadas, ${ }^{67}$ lo que hace que el número de veinticuatro destacado por Pina sea modesto y más que plausible.

Hacia 1740 su Orden lo destinó a Levante donde diseñó y dirigió numerosas obras. Allí trabajó, entre otras muchas localidades, en Játiva, ${ }^{68}$ Onteniente y Valencia capital, ${ }^{69}$ e incluso entregó un proyecto para la iglesia arciprestal de Villarreal (Castellón) que finalmente sería rechazado en favor del de Juan José Nadal. ${ }^{70}$ Falleció siendo conventual de Játiva el 6 de febrero de $1772,{ }^{71}$ tras haber obtenido el título real de maestro arquitecto y el grado de académico de mérito de la Academia de San Carlos de Valencia en $1769 .^{72}$ Resulta relevante indicar que, en la súplica enviada por el propio religioso a la Academia, cuya sección de arquitectura estaba dirigida para entonces por Vicente Gascó y Antonio Gilabert, manifestó que él era el "mas antiguo arquitecto que se conoce en este Reyno", a la vez que destacó su labor de intrucción a diferentes arquitectos en tierras levantinas, entre los que se encontrarían su sobrino fray Francisco de Santa Bárbara y Jaime Pérez. ${ }^{73}$ Como apoyo al memorial presentado a la Academia, fray José Alberto diseñó varios planos de los que se han conservado los cuatro correspondientes a dos proyectos para la iglesia de las Escuelas Pías de Valencia, cuyos dibujos fueron publicados por Salvador Aldana. ${ }^{74}$ Aunque ninguno de los dos llegó a materializarse, la propuesta de planta centralizada del segundo proyecto resulta muy próxima a la solución empleada por este fraile arquitecto en las trazas de las fábricas levantadas en la ciudad de Tudela, y, especialmente, para la sacristía de la colegiata de Santa María de Calatayud, circunstancia que podría acreditar su autoría.

\section{Maestro de obras, albañil, alarife o arquitecto: ¿una cuestión terminológica?}

Una de las cuestiones que consideramos interesante destacar del pleito analizado es el empleo de los términos maestro de obras, albañil, alarife y arquitecto de manera indistinta. Como la profesora Blasco Esquivias ha dedicado recientemente una espléndida monografía a tratar de dilucidar esta cuestión, ${ }^{75}$ tomaremos como referencia su trabajo con el propósito de aproximarnos a ella aunque vinculándola con la figura de Pina.

En primer lugar, el Diccionario de autoridades (1726-1739) recoge que alarife es "el Maestro que publicamente está señaládo y aprobádo para reconocer, apreciar, ù dirigir las obras que pertenécen à la Architectúra; aunque yá generalmente se toma solo por el Maestro de Albañilería". Por su parte, albañil se refería al "artifice que labra ò edifica casas, sirviendose solamente de materiáles menúdos, como son cal, hyeso, barro, ladrillo, teja, rípio, etc. à diferéncia del cantéro, que usa, y se sirve de piedra, y labra y ajusta", mientras que maestro de obras era "lo mismo que Architecto". Por último, arquitecto era definido como "el Ma-

\footnotetext{
${ }^{66}$ EXPÓSITO SEBASTIÁN, Manuel, 1992, p. 84.

67 CANO SANZ, Pablo, 2005, p. 31.
}

${ }^{68}$ ALDANA FERNÁNDEZ, Salvador, "Fray José Pina, arquitecto del siglo XVIII". Archivo Español de Arte, t. XXXI, n 121, 1958, pp. 49-57, esp. pp. 51-55; BÉRCHEZ, Joaquín y GÓMEZ-FERRER, Mercedes, "Visiones y mentalidad arquitectónica de un maestro del siglo XVIII. La Descripción breve de las medidas y magnificencia... del convento de Santa Clara de Játiva, por fray José Alberto Pina". Ars Longa, 14-15, 2005-2006, pp. 195-216; y BÉRCHEZ, Joaquín y GÓMEZ-FERRER, Mercedes, La Seo de Xàtiva. Historia, imágenes y realidades. Valencia: Institut Valencià de Conservació y Restauració de Béns Culturals, 2007, pp. 28-32.

69 BÉRCHEZ, Joaquín, Arquitectura barroca valenciana. Valencia: Bancaja, 1993, pp. 156-162.

70 GIL SAURA, Yolanda, Arquitectura Barroca en Castellón. Castellón: Diputación de Castellón, 2004, pp. 196-198 y 344-349; y BAUTISTA I GARCÍA, Joan Damià, Esglésies-saló del segle XVIII a les comarques valencianes. Castellón: Fundación Dávalos-Fletcher, 2002, pp. 201-207.

71 ORELLANA, Marcos Antonio de, 1967, p. 544 y doc. $n^{\circ}$ IX, p. 580

72 BÉRCHEZ, Joaquín, 1993, p. 156.

73 BÉRCHEZ, Joaquín y GÓMEZ-FERRER, Mercedes, 2005-2006, pp. 196-197.

74 ALDANA FERNÁNDEZ, Salvador, 1958, lám. II.

75 BLASCO ESQUIVIAS, Beatriz, Arquitecto y tracistas. El triunfo del Barroco en la corte de los Austrias. Madrid: Centro de Estudios Europa Hispánica, 2013. 
estro de obras que idéa y traza las fábricas y los edificios". ${ }^{76}$

Como es sabido, desde la definición de arquitecto que León Bautista Alberti ofreció en su tratado De re aedificatoria a mediados del siglo $\mathrm{XV}$, la labor de este profesional se dividía en dos partes: proyectar los edificios, pero también tener la facultad de llevar a la práctica cualquier obra. ${ }^{77}$ Esta moderna concepción de arquitecto como tracista o inventivo llegó a España de la mano de las Medidas del Romano (1526) de Diego de Sagredo. El burgalés destacó la función intelectual del arquitecto en la disposición del edificio frente "a los oficiales de manos". Pese a ello, en nuestro país se empleaba el término de maestro de obras como sinónimo. ${ }^{78}$ De hecho, desde el punto de vista semántico, la profesora Blasco asegura que el vocablo "arquitecto" nunca se llegó a manejar con el significado definido por Alberti, "sino que los individuos de esta profesión siguieron utilizándolo indistintamente junto a la más tradicional denominación de maestro de obras, sirviéndose de una u otra según el contexto laboral", ${ }^{79}$ afirmación que corrobora el Tesoro de la lengua castellana o española de Sebastián de Covarrubias, publicado en Madrid en $1611 .{ }^{80}$ No obstante, parece que fue en la edificación del monasterio de El Escorial cuando, al menos oficialmente, se produjo la separación entre el arquitecto inventivo y el arquitecto técnico o práctico. ${ }^{81}$ Esta división teóricopráctica del arquitecto permanecerá en España a lo largo del siglo XVII llegando hasta el XVIII, como se aprecia en los tratados de fray Lorenzo de San Nicolás, Juan de Torija o Teodoro Ardemans, ${ }^{82}$ textos que, como veremos, Pina conocía.

Sin embargo, en la documentación localizada hasta el momento redactada y firmada autógrafamente por fray José Alberto Pina, el carmelita se sirve de ambos términos a la vez para referirse a sí mismo, probablemente con la intención de hacer constar su pericia tanto de la parte práctica como de la teórica del oficio. Así sucede en la visura de la piedra que el cantero Juan de Estanga estaba utilizando en la construcción del nuevo pórtico de la catedral de Tarazona suscrita el 7 de diciembre de 1733 en la que se reconoce como "architecto y maestro de obras". ${ }^{83}$ De este modo, el religioso dejaba clara su capacidad para asumir la responsabilidad de todo el proceso arquitectónico, desde la traza hasta la fábrica, además de su conocimiento profundo de los materiales.

No obstante, en los casos en los que Pina solo debía destacar su labor como tracista firmó únicamente como "architecto", como hizo en la declaración que redactó para tratar de dirimir las diferencias entre las religiosas de la Compañía de María de Tudela y el chantre y canónigo Agustín de Ichaso acerca de la obra del propio carmelita, documento de 25 de agosto de 1733 en el que se autodenominó "architecto de fabrica". ${ }^{84}$ Igualmente, el 6 de noviembre del mismo año suscribió la capitulación para la construcción del nuevo pórtico de la catedral turiasonense diseñado por él mismo como "architecto carmelita observante". ${ }^{85}$

Al margen del sistema de aprendizaje del taller y de las maestranzas, en el que, como vimos, fray José Alberto comenzó su adiestramiento, durante la Edad Moderna los profesionales de la construcción adquirieron su formación gracias al desarrollo de su propia actividad laboral complementándola de modo autodidacta con lecturas especializadas. ${ }^{86}$ En efecto, la formación del carmelita fue sólida y su conocimiento de la teoría arquitectónica debió ser amplio como queda patente tanto en sus informes como en sus diseños. Gracias a ellos podemos asegurar que manejó las Ordenanzas de

\footnotetext{
76 Términos consultados en el Diccionario de autoridades en línea en http://web.frl.es/DA.html (fecha de consulta: 30/03/2018). Véase asimismo GÓMEZ LÓPEZ, Consuelo, "Los Alarifes en los oficios de la construcción (siglos XV-XVIII)". Espacio, Tiempo y Forma, Serie VII, Historia del Arte, 4, 1991, pp. 39-51.

77 BLASCO ESQUIVIAS, Beatriz, 2013, p. 21.

78 Ibidem, pp. 32-33.

79 Ibidem, p. 34. Véase asimismo el interesante trabajo del profesor Marías donde aborda esta cuestión MARÍAS, Fernando, "El problema del arquitecto en la España del siglo XVI". Academia, 48, 1979, pp. 175-216.

80 Las definiciones de arquitecto y maestro de obras de Covarrubias se recogen en BLASCO ESQUIVIAS, Beatriz, 2013, p. 35.

81 Ibidem, pp. 35 y 45.

82 Acerca de esta cuestión véase ibidem, pp. 36-37.

83 CARRETERO CALVO, Rebeca, 2016-2017, doc. n³, pp. 48-50.

84 AZANZA LÓPEZ, José Javier, 1998 a, p. 15.

85 CARRETERO CALVO, Rebeca, 2016-2017, doc. n², pp. 43-48.

86 Véase GARCÍA MORALES, Ma Victoria, La figura del arquitecto en el siglo XVII. Madrid: Universidad Nacional de Educación a Distancia, 1991, pp. 130-138; y BLASCO ESQUIVIAS, Beatriz, 2013, p. 29.
} 
Teodoro Ardemans y de Juan Torija, y que los citó en un pleito suscitado entre las religiosas de la Compañía de María de Tudela y Antonio Merino sobre la apertura de un vano que ponía en peligro la intimidad de la clausura a comienzos de 1734. ${ }^{87}$ Además, como destacó el profesor Azanza López, en esta iglesia tudelana Pina demostró conocer el tratado L'architetto prattico de Giovanni Biagio Amico, cuyo primer volumen vio la luz en Palermo en 1726, quien recomendaba la construcción de edificios de planta central con deambulatorio para los templos jesuíticos. Asimismo, el empleo del entablamento que se vuelve convexo a la altura de los soportes demuestra que se sirvió del Perspectiva pictorum et architectorum de Andrea Pozzo, publicado en dos volúmenes en Roma en 1693 y 1700. Aparte de ello, este mismo texto le sirvió de fundamento en el trazado de varias de las obras navarras y aragonesas mencionadas. ${ }^{88}$ Igualmente, es preciso destacar que la disposición de las figuras de los Evangelistas y los Padres de la Iglesia sobre las columnas evoca tanto a los dibujos de Giovanni Giocondo Veronese para su edición de Los diez libros de arquitectura de Vitruvio de comienzos del siglo XVI como a los de Juan Caramuel contenidos en su Arquitectura Civil Recta $y$ Oblicua de $1678{ }^{89}$

A todo este bagaje hay que añadir que a mediados del siglo XVIII el propio Pina redactó la Descripción breve de las medidas y magnificencia en que se haIla construido el Real Monasterio de las muy ilustres señoras religiosas de la madre Santa Clara edificado [...] en Játiva, texto en el que hace gala de una sólida formación tanto práctica como teórica, a la vez que deja patente su concepción arquitectónica. ${ }^{90}$ Además, en su título quiso destacar su calidad de "maestro de obras y architecto de su Magestad, actualmente director y tracista de la Muy Insigne fabrica de la Colegial de dicha Ciudad". ${ }^{91}$

\section{Conclusiones}

Como hemos podido comprobar, el enfrentamiento legal entre fray José Alberto Pina y el gremio de albañiles de Zaragoza puso en evidencia una fuerte tensión contenciosa que escondía los intereses de una y otra parte. Por un lado, el carmelita deseaba obtener el reconocimiento oficial de su profesión iniciada en la ciudad del Ebro con los maestros de obras Lamberto Tarazona y José Borgas. Aunque las razones no se especifican, se puede considerar que, al margen de la posible vocación religiosa del joven, Pina ingresó en religión en un momento en el que los conventos carmelitanos zaragozanos iniciaron la renovación de sus casas con el propósito de ganarse la vida, asegurarse un futuro profesional duradero y una establidad personal, y evitando la competencia. ${ }^{92} \mathrm{De}$ este modo, alcanzando el grado de maestro, podría disponer de oficiales para que trabajaran en las obras por él dirigidas. Por otro lado, el gremio, apoyado por la autoridad municipal, se negó obstinadamente a allanarle el terreno urdiendo todas las excusas posibles incluso poniendo en duda la profesionalidad del fraile para proteger a sus asociados de esa concurrencia, defendiendo la tradición y, sobre todo, la endogamia corporativa puesto que Pina ni pertenecía a la familia de ningún agremiado ni era natural de Zaragoza.

En definitiva, el gremio, aún con la ley en su contra, hizo gala de su poder ${ }^{93}$ preservando sus intereses sin dar pie a ningún tipo de negociación entre las partes y mostrándose totalmente inflexible con fray José Alberto Pina, aunque no en otros casos que fueron recordados en la causa. Ante ello, el carmelita, a través de su procurador, mostró su fuerte carácter y su personalidad, así como su dominio de la expresión escrita, faceta que desarrollará en sus textos arquitectónicos redactados con posterioridad.

\footnotetext{
87 AZANZA LÓPEZ, José Javier, 1998 a, p. 16.

88 Como se estudia en CARRETERO CALVO, Rebeca, 2017, pp. 131-132.

${ }^{89}$ AZANZA LÓPEZ, José Javier, 1998 a, pp. 16-17.

90 BÉRCHEZ, Joaquín y GÓMEZ-FERRER, Mercedes, 2005-2006, pp. 195-216.

91 Ibidem, p. 195.
}

92 Según expresa Paula Pita, solo la Orden del Císter no admitió este tipo de vocaciones de seglares con profesiones relacionadas con la edilicia, en PITA GALÁN, Paula, "Arquitectos, maestros de obras, canteros y carpinteros: los frailes legos en la fábrica del convento de San Francisco de Santiago". Ad Limina, vol. 5, n 5, 2014, pp. 106-107.

${ }^{93}$ Aún cuando pocas décadas más tarde el sistema gremial comenzaría a ser abolido. Sobre esta cuestión véase, por ejemplo, BELDA NAVARRO, Cristóbal, y DE LA PEÑA VELASCO, Concepción, "La visión de un mundo en crisis: Los gremios frente a la Academia". En: Actas del IX Congreso Español de Historia del Arte. León: Universidad de León, 1994, pp. 17-25; y REDONDO CANTERA, Ma José, "Canteros, maestros de obras y académicos: Un pleito sobre titulación para el ejercicio de la arquitectura tras la Real Orden de 1787". Boletín del Seminario de Estudios de Arte y Arqueología, 63, 1997, pp. 539-554. 
Aparte de lo anterior, el pleito aquí presentado ofrece una amplia nómina de artífices y una información hasta ahora totalmente desconocida que debe convertirse en el punto de partida de futuras investigaciones sobre la organización y el comportamiento del gremio de albañiles y sobre la actividad edilicia en Zaragoza durante la primera mitad del siglo XVIII, años en los que se estaba edificando la nueva basílica-catedral de Nuestra Señora del Pilar que, debido a su trascendencia tanto devocional como artística, ha eclipsado casi por completo en la historiografía al resto de fábricas.

El caso de fray José Alberto Pina incide en la intensa labor arquitectónica que estos religiosos mantuvieron fuera del seno de sus órdenes, circunstancia al parecer aceptada de buen grado por sus superiores porque constituía una importante fuente de ingresos para sus conventos. ${ }^{94}$ Sin embargo, no sería tolerada por el gremio pues, como hemos podido comprobar en el análisis del pleito zaragozano, este pergeñó todo tipo de excusas y justificaciones para evitar el acceso de este importante arquitecto aragonés al grado de maestro, lo que finalmente no obstó para que el carmelita desarrollara su profesión tanto fuera como dentro de su Orden, aunque, eso sí, lejos de la ciudad de Zaragoza.

\section{Bibliografía}

ABADÍA TIRADO, José. "Fray José Alberto Pina: El Arquitecto (1)". El Gallico de Moyuela, 79, 2013, p. 11.

AGUILERA HERNÁNDEZ, Alberto. "La cofradía de San José de la ciudad de Borja: su fundación en la colegiata de Santa María y el exorno de su capilla titular (1625-1694)". Artigrama, 30, 2015, pp. 241-259.

ALDANA FERNÁNDEZ, Salvador. "Fray José Pina, arquitecto del siglo XVIII". Archivo Español de Arte, t. XX$\mathrm{XI}, \mathrm{n}^{\circ} 121,1958$, pp. 49-57.

ALMAGRO GORBEA, Antonio y ARCE OLIVA, Ernesto. Palacio Episcopal de Albarracín. Zaragoza: Fundación Santa María de Albarracín, 2011.

ALMERÍA, José Antonio et al. Las artes en Zaragoza en el último tercio del siglo XVII (1676-1696). Estudio documental. Zaragoza: Institución "Fernando el Católico", 1983.

ANSÓN NAVARRO, Arturo. "El gremio de doradores de Zaragoza (1675-1820)". En: Homenaje a don Federico Balaguer Sánchez. Huesca: Instituto de Estudios Altoaragoneses, 1987, pp. 485-511.

ANSÓN NAVARRO, Arturo. El entorno del Convento del Carmen de Zaragoza. Una reconstrucción histórica y artística. Siglos XIII al XX. Zaragoza: Elazar Ediciones, 2007.

AZANZA LÓPEZ, José Javier. "Tracistas y maestros de obras aragoneses en la arquitectura barrroca navarra". Boletín del Museo e Instituto "Camón Aznar" LXXI, 1998 a, pp. 5-24.
AZANZA LÓPEZ, José Javier. Arquitectura religiosa del barroco en Navarra. Pamplona: Gobierno de Navarra, 1998b.

AZANZA LÓPEZ, José Javier. Arquitectura y religiosidad barrocas en Villafranca (Navarra). Villafranca: Parroquia de Santa Eufemia de Villafranca y Departamento de Historia del Arte de la Universidad de Navarra, 1999.

BALLESTÍN MIGUEL, José Miguel. Zaragoza según el plano de 1712 y su vecindario de 1723. Zaragoza: Institución "Fernando el Católico", 2017.

BAUTISTA I GARCÍA, Joan Damià. Esglésies-saló del segle XVIII a les comarques valencianes. Castellón: Fundación Dávalos-Fletcher, 2002.

BELDA NAVARRO, Cristóbal, y DE LA PEÑA VELASCO, Concepción. "La visión de un mundo en crisis: Los gremios frente a la Academia". En: Actas del IX Congreso Español de Historia del Arte. León: Universidad de León, 1994, pp. 17-25.

BÉRCHEZ, Joaquín. Arquitectura barroca valenciana. Valencia: Bancaja, 1993.

BÉRCHEZ, Joaquín y GÓMEZ-FERRER, Mercedes. "Visiones y mentalidad arquitectónica de un maestro del siglo XVIII. La Descripción breve de las medidas y magnificencia... del convento de Santa Clara de Játiva, por fray José Alberto Pina". Ars Longa, 14-15, 2005-2006, pp. 195-216.

BÉRCHEZ, Joaquín y GÓMEZ-FERRER, Mercedes. La Seo de Xàtiva. Historia, imágenes y realidades. Valencia: Institut Valencià de Conservació y Restauració de Béns Culturals, 2007.

BLASCO ESQUIVIAS, Beatriz. Arquitecto y tracistas. El triunfo del Barroco en la corte de los Austrias. Madrid: Centro de Estudios Europa Hispánica, 2013.

BOLOQUI LARRAYA, Belén. Escultura zaragozana en la época de los Ramírez. 1710-1780. 2 vols. Madrid: Ministerio de Cultura, 1983.

BRUÑÉN IBÁÑEZ, Ana Isabel; CALVo COMÍN, Ma Luisa y SENAC RUBIO, $\mathrm{M}^{\mathrm{a}}$ Begoña. Las artes en Zaragoza en el tercer cuarto del siglo XVII (1655-1675). Estudio documental. Zaragoza: Institución "Fernando el Católico", 1987.

CANO SANZ, Pablo. Fray Antonio de San José Pontones: arquitecto, ingeniero y tratadista en España, (17101774). Madrid: Universidad Complutense de Madrid, 2004.

CANO SANZ, Pablo. Fray Antonio de San José Pontones. Arquitecto jerónimo del siglo XVIII. Madrid: Consejo Superior de Investigaciones Científicas, 2005.

CARRERAS ASENSIO, José $\mathrm{M}^{\mathrm{a}}$. "Ermitas barrocas de planta de cruz griega, cúpula y brazos semicirculares en el área de Daroca". Xiloca, 32, 2004, pp. 39-56.

CARRETERO CALVO, Rebeca. "La iglesia de San Atilano construida sobre su casa natal". En: CARRETERO CALVO, R. y CRIADO MAINAR, J. (coords.). MILENIO. San Atilano y Tarazona (1009-2009). Tarazona: Fundación Tarazona Monumental, 2009, pp. 111-133.

CARRETERO CALVO, Rebeca. "El gremio de albañiles y carpinteros de Tarazona durante la Edad Moderna". Artigrama, 26, 2011, pp. 603-624.

94 CANO SANZ, Pablo, 2005, p. 63. Fray Lorenzo de San Nicolás también trabajó fuera del seno de su Orden, como se pone de manifiesto en DÍAZ MORENO, Félix, "Construir con palabras. El vocabulario artístico en el tratado de fray Lorenzo de san Nicolás". En: LAHOZ, L. y PÉREZ HERNÁNDEZ, M. (eds.), Lienzos del recuerdo. Estudios en homenaje a José Ma Martínez Frías. Salamanca: Ediciones Universidad de Salamanca, 2015, p. 188. 
CARRETERO CALVO, Rebeca. Arte y arquitectura conventual en Tarazona en los siglos XVII y XVIII. Tarazona: Centro de Estudios Turiasonenses y Fundación Tarazona Monumental, 2012.

CARRETERO CALVO, Rebeca y ANSÓN NAVARRO, Arturo. "La Catedral de Tarazona en los siglos del Barroco". En: La catedral de Santa María de la Huerta de Tarazona. Zaragoza: Diputación Provincial de Zaragoza, 2013, pp. 195-227.

CARRETERO CALVO, Rebeca. "El arquitecto fray José Alberto Pina y la sacristía de la Colegiata de Santa María de Calatayud". En: IX Encuentro de Estudios Bilbilitanos. 2 vols. Calatayud: Centro de Estudios Bilbilitanos, 2016, vol. II, pp. 767-782.

CARRETERO CALVO, Rebeca. "La catedral de Tarazona en el siglo XVIII: Renovación artística y transformaciones arquitectónicas". Tvriaso, XXIII, 2016-2017, pp. 9-52.

CARRETERO CALVO, Rebeca. "Recepción del tratado del jesuita Andrea Pozzo en Aragón". Locus Amoenus, 15, 2017, pp. 117-138.

CRIADO MAINAR, Jesús. Las artes plásticas del Segundo Renacimiento en Aragón. Pintura y Escultura 15401580. Tarazona: Centro de Estudios Turiasonenses e Institución "Fernando el Católico", 1996.

DÍAZ MORENO, Félix. Fray Lorenzo de San Nicolás: Arte y vso de arquitectvra. Edición anotada. Madrid: Instituto de Estudios Madrileños, 2008.

DÍAZ MORENO, Félix. "Construir con palabras. El vocabulario artístico en el tratado de fray Lorenzo de san Nicolás". En: LAHOZ, L. y PÉREZ HERNÁNDEZ, M. (eds.). Lienzos del recuerdo. Estudios en homenaje a José Ma Martínez Frías. Salamanca: Ediciones Universidad de Salamanca, 2015, pp. 185-192.

ECHEVERRÍA GOÑI, Pedro Luis y FERNÁNDEZ GRACIA, Ricardo. "Arquitectura religiosa de los siglos XVI al XVIII en Navarra". En: Ibaiak eta Haranak, Guía del patrimonio histórico-artístico-paisajístico. 10 vols. San Sebastián: Etor, vol. 8, 1991.

ESCRIBANO SÁNCHEZ, José Carlos. "El pórtico de la Catedral de Tarazona". Hydria, 2, 1997, pp. 10-11.

ESTEBAN LORENTE, Juan Francisco. La platería de Zaragoza en los siglos XVII y XVIII. 3 vols. Madrid: Ministerio de Cultura, 1981.

EXPÓSITO SEBASTIÁN, Manuel. "El gremio de albañiles de Zaragoza (1775-1806)". Artigrama, 2, 1985, pp. 161 176

EXPÓSITO SEBASTIÁN, Manuel. "El gremio de canteros de Zaragoza (1760-1812)". Artigrama, 1, 1984, pp. 269286.

EXPÓSITO SEBASTIÁN, Manuel. “Precisiones sobre la construcción durante el siglo XVIII, de la iglesia parroquial de Luna (Zaragoza)". Suessetania, 12, 1992, pp. 81-98.

FERNÁNDEZ GRACIA, Ricardo. El retablo barroco en Navarra. Pamplona: Gobierno de Navarra, 2003.

GARCÍA DE PASO REMÓN, Alfonso. La Iglesia Parroquial de San Gil Abad de Zaragoza. Zaragoza: Institución "Fernando el Católico", 1985.

GARCÍA GAINZA, Ma Concepción (dir.). Catálogo monumental de Navarra, I. Merindad de Tudela. Pamplona: Institución Príncipe de Viana, Arzobispado de Pamplona y Universidad de Navarra, 2003 (1ª reimp.; $1^{\mathrm{a}}$ ed. de 1980).
GARCÍA MORALES, Ma Victoria. La figura del arquitecto en el siglo XVII. Madrid: Universidad Nacional de Educación a Distancia, 1991.

GÓMEZ LÓPEZ, Consuelo. "Los Alarifes en los oficios de la construcción (siglos XV-XVIII)". Espacio, Tiempo y Forma, Serie VII, Historia del Arte, 4, 1991, pp. 39-51.

GÓMEZ URDÁÑEZ, Carmen. "La 'puerta mayor' de la catedral de Tarazona. Del siglo XIII al siglo XX". En RAMALLO ASENSIO, G. A. (coord.). Las catedrales españolas del Barroco a los Historicismos. Murcia: Universidad de Murcia y Gobierno de la Región de Murcia, 2003, pp. 343-345.

GÓMEZ URDÁÑNEZ, Carmen. Arquitectura civil en Zaragoza en el siglo XVI. 2 vols. Zaragoza: Ayuntamiento de Zaragoza, 1987-1988.

GONZÁLEZ HERNÁNDEZ, Vicente. "Cofradías y gremios zaragozanos en los siglos XVI y XVII: La Cofradía de San Lucas de pintores". Zaragoza, XXV, 1967, pp. 175-190.

LÓPEZ-MELUS, Rafael Ma. VII Centenario del Carmelo de Zaragoza. Zaragoza: Amacar, 1991.

MARÍAS, Fernando. "El problema del arquitecto en la España del siglo XVI". Academia, 48, 1979, pp. 175-216.

MARTÍNEZ VERÓN, Jesús. Arquitectos en Aragón. Diccionario histórico. 5 vols. Zaragoza: Institución "Fernando el Católico", 2000-2001.

MUÑOZ JIMÉNEZ, José Miguel. Fray Alberto de la Madre de Dios. Arquitecto (1575-1635). Santander: Ediciones Tantín, 1990.

NARVÁEZ CASES, Carme. El tracista Fra Josep de la Concepció (1626-1690). Barcelona: Curial Edicions Catalanes y Fundació Abadia de Monserrat, 2004.

NARVÁEZ CASES, Carme. El tracista fra Josep de la Concepció i l'arquitectura carmelitana a Catalunya. Barcelona: Universidad Autónoma de Barcelona, 2000.

ORELLANA, Marcos Antonio de. Biblioteca Pictórica Valentina o Vida de los pintores, arquitectos, escultores y grabadores valencianos ( $2^{\mathrm{a}}$ ed. de Xavier de Salas). Valencia: Ayuntamiento de Valencia, 1967.

PITA GALÁN, Paula. "Arquitectos, maestros de obras, canteros y carpinteros: los frailes legos en la fábrica del convento de San Francisco de Santiago". Ad Limina, vol. 5, n 5, 2014, pp. 103-119.

REDONDO CANTERA, Ma José. "Canteros, maestros de obras y académicos: Un pleito sobre titulación para el ejercicio de la arquitectura tras la Real Orden de 1787". Boletín del Seminario de Estudios de Arte y Arqueología, 63, 1997, pp. 539-554.

REDONDO VEINTEMILLAS, Guillermo. Las corporaciones de artesanos de Zaragoza en el siglo XVII. Zaragoza: Institución "Fernando el Católico", 1982.

SAN VICENTE PINO, Ángel. La platería de Zaragoza en el Bajo Renacimiento (1545-1599). 3 vols. Zaragoza: Libros Pórtico, 1976.

SÁNCHEZ MARTÍNEZ, Concepción. Estudio histórico-artístico de la Iglesia de Nuestra Señora del Portillo de Zaragoza. Zaragoza: Institución "Fernando el Católico", 1983.

VELASCO BAYÓN, Balbino. Historia del Carmelo español. 3 vols. Roma: Edizioni Carmelitane, 1990-1994.

ZORROZUA SANTISTEBAN, Julen. "Un retablo barroco procedente de Zaragoza en la iglesia bilbaína del Pilar". Artigrama, 18, 2003, pp. 435-446. 